\title{
Ecoenvolventes: análisis del uso de fachadas ventiladas en clima cálido-húmedo
}

\author{
Sara Luciani-Mejía, Rodrigo Velasco-Gómez, Roland Hudson \\ Universidad Piloto de Colombia, Bogotá (Colombia) \\ Facultad de Arquitectura y Artes, Programa de Arquitectura \\ Grupo de investigación $\mathrm{HD}+\mathrm{i}$
}

uciani-Mejía, S., Velasco-Gómez,

R., \& Hudson, R. (2018)

Ecoenvolventes: análisis del

uso de fachadas ventiladas

en clima cálido-húmedo.

Revista de Arquitectura (Bo-

gotá), 20(2), 62-77. Doi:

http://dx.doi.org/10.14718/

RevArq.2018.20.2.1726

http://dx.doi.org/10.14718/RevArq.2018.20.2.1726

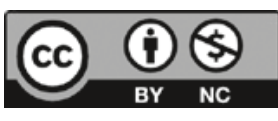

\author{
Sara Luciani-Mejía
Arquitecta, Universidad Piloto de Colombia, Bogotá (Colombia).
}

Maestría en Gestión Urbana, Universidad Piloto de Colombia, Bogotá (Colombia)

Docente-investigador, Universidad Piloto de Colombia.

Publicaciones recientes

(20I5). Simulaciones ambientales para la selección de materiales en diseño de alojamientos temporales en climas tropicales. Revista de Arquitectura, 16, 96- 104.

(D) https://orcid.org/0000-0003-3243-6370

sara-luciani@unipiloto.edu.co

Rodrigo Velasco-Gómez

Arquitecto, Universidad Nacional de Colombia, Bogotá (Colombia).

M. Eng in Computational Design, Ostwestfalen-Lippe University of Applied Sciences, Detmold (Alemania). Docente-investigador, Universidad Piloto de Colombia (Colombia).

Desarrollo de investigación de doctorado titulada Fibre Reinforced Plastics in the Construction of Buildings Envelopes, University of Nottingham, UK, 2000-2005

Publicaciones recientes

(20I5). Notes on the design process of a responsive sun-shading system: A case study of designer and user explorations supported by computational tools. Aiedam, 29 (04), 483-502.

(D) https://orcid.org/0000-0002-4108-3805

rodrigo-velasco@unipiloto.edu.co

Roland Hudson

BSc General Architecture Studies, University of Bath (Reino Unido)

MSc Software Engineering, University of Liverpool (Reino Unido)

Master of Architecture, University of Bath (Reino Unido).

$\mathrm{PhD}$, University of Bath (Reino Unido).

Profesor de cátedra, Universidad de Los Andes

Publicaciones recientes

Rodríguez, C., Niblock, C. y Hudson, R. (2017). Collaborative learning in architectural education: Benefits of combining conventional studio, virtual design studio (VDS) and live projects. British Journal of Educational Technology.

(D) https://orcid.org/0000-000I-5605-0187

roland-hudson@unipiloto.edu.co

\section{Resumen}

Con el objetivo de aportar a la reducción de impactos en la construcción de edificaciones fueron diseñados varios sistemas de fachadas ventiladas y convencionales, involucrando fachadas opacas, elementos vegetales y cámaras de aire. Tales sistemas fueron evaluados con simulaciones ambientales y mediciones en prototipo en las diversas etapas de la investigación, lo que permitió la comparación de resultados y la identificación de comportamiento en términos de confort térmico. Los resultados de las simulaciones frente a mediciones vislumbraron dos cuestiones: las discrepancias y similitudes entre los datos de entrada y salida en los dos tipos de proceso mencionados; así como la utilidad de las fachadas ventiladas opacas en clima tropical húmedo como Girardot, lo que sugirió una última etapa de evaluación de estrategias de diseño pasivo en la búsqueda del confort térmico y la sostenibilidad en el proyecto arquitectónico.

Palabras clave: arquitectura bioclimática, clima, datos climáticos, diseño arquitectónico, modelo de simulación, temperatura. Eco-friendly coverings: Analysis of the use of ventilated facades in hot, humid weather

\section{Abstract}

Aiming to contribute to impact reduction in the construction of buildings, various systems of ventilated and conventional facades were designed, involving opaque facades, plant elements, and air chambers. Such systems were evaluated through environmental simulations and prototype measurements at various stages of the project, which allowed comparing results and identifying their behavior in terms of thermal comfort. The results of these simulations compared against measurements highlighted two issues: discrepancies and similarities between inputs and outputs in the above mentioned two process types; as well as the performance of opaque ventilated facades in humid tropical climate such as in Girardot, which suggested a last stage to evaluate passive design strategies in search for thermal comfort and sustainability in architectural projects.

Keywords: Bioclimatic architecture, climate, climatic data, architectural design, simulation model, temperature.

Ecoenvolventes: análise do uso de fachadas ventiladas em clima quente e úmido

\section{Resumo}

Com o objetivo de contribuir com a redução de impactos na construção de prédios foram desenhados vários sistemas de fachadas ventiladas e convencionais, que envolvem fachadas opacas, elementos vegetais e duto de ar. Esses sistemas foram avaliados com simulações ambientais e medições em protótipo nas diversas etapas da investigação, o que permitiu a comparação de resultados e a identificação de comportamento em termos de conforto térmico. Os resultados das simulações ante medições vislumbraram duas questões: as discrepâncias e as semelhanças entre os dados de entrada e saída nos dois tipos de processo mencionados, assim como a utilidade das fachadas ventiladas opacas em clima tropical úmido, como Girardot (Colômbia), o que sugeriu uma última etapa de avaliação de estratégias de desenho passivo na busca de conforto térmico e de sustentabilidade no projeto arquitetônico.

Palavras-chave: arquitetura bioclimática, clima, dados climáticos, desenho arquitetônico, modelo de simulação, temperatura. 


\section{Introducción}

La investigación denominada Ecoenvolventes, desarrollada por la Universidad Piloto de Colombia en las sedes de Bogotá y Girardot, tuvo como fin aportar información para contribuir a la reducción de impactos en la construcción de edificaciones y mejorar el confort térmico; esto llevó a considerar diversas estrategias para la proyección de construcciones sostenibles tales como las fachadas ventiladas.

Estas son definidas por Barbosa e Ip (2014, p. 1021) como una fachada tradicional con una cámara de aire y una piel externa adicional, usualmente en vidrio, con circulación de aire controlada entre capas. Ante esto, Ciampi, Leccese y Tuoni (2003, p. 491); Afonso y Oliveira (2000, p. 79); Balocco (2002, p. 469) y Marinosci, Strachan, Semprini y Morini (2011, p. 287) demuestran que una fachada ventilada diseñada de forma adecuada puede ayudar a reducir las cargas de calor producidas por la radiación solar.

Asimismo, Theodosiou, Tsikaloudakia y Bikas (2017, p. 397); Ghaffarianhoseini, Ghaffarianhoseini, Berardi, Tookey, Hin Wa Li y Kariminia (2016, p. 1053); Høseggen, Wachenfeldt y Hanssen (2008, p. 821) y Poirazis (2004, p. 61), mencionan que las fachadas ventiladas presentan ventajas sobre las fachadas simples en varios aspectos como eficiencia térmica en la medida en que funciona como aislamiento térmico y reduce la demanda de sistemas activos (HVAC); reducción de niveles de ruido al interior de las edificaciones por transmisión entre los espacios y desde el exterior, lo que permite la ventilación natural en sitios donde normalmente no es posible por los altos niveles de ruido; además de protección frente a la radiación solar, polución y condiciones adversas del clima; reducción de los efectos de presión del viento; resistencia al fuego y eficiencia estructural.

Por otra parte, Haase, Silva y Amato (2009, p. 361); Høseggen et al. (2008, p. 821) y Poirazis (2004, p. 66), señalan como desventajas la reducción del espacio útil de la construcción, el costo considerablemente alto con respecto a las fachadas tradicionales (en promedio un 60 a $80 \%)$, los costos adicionales de operación y mantenimiento, el incremento en el peso de la estructura que repercute en el incremento de costos, y el riesgo de sobrecalentamiento al interior del espacio en clima cálido, a causa de un diseño inapropiado.

Ante las desventajas del uso de fachadas ventiladas transparentes en clima cálido, Peci, Jensen, Heiselberg y Ruiz de Adana (2012, p. 265) proponen como alternativa el uso de fachadas ventiladas opacas en la cuales las dos superficies son opacas, condición que permite la absorción de la radiación solar por la superficie externa y reduce el riesgo de sobrecalentamiento; además de considerar un menor costo debido a la posibilidad de ser construidas en materiales convencionales y la reducción de aproximadamente el $58 \%$ de cargas térmicas con respecto a las fachadas tradicionales, según estudios realizados por Fantucci, Marinosci, Serra y Carbonaro (2017, p. 619).

No obstante, en cuanto al estudio de fachadas ventiladas opacas, Marinosci, Semprini y Morini (2014, p. 280); Marinosci, Strachan, Semprini y Morini (2011, p. 854); Aparicio, Vivancos, Ferrer y Royo (2014, p. 564) mencionan que este tipo de fachadas ha recibido menos atención que otras configuraciones con vidrio, y Giancola, Sanjuan, Blanco y Heras (2012, p. 363) sugieren que existen todavía menos estudios sobre el desempeño energético de las mismas; asimismo, Barbosa e Ip (2014, p. 1020) afirman que se requiere mayor investigación para la comprensión de los procesos relacionados con las fachadas ventiladas y las implicaciones de su uso en diversas condiciones climáticas, razón por la cual esta investigación se centra en el uso de fachadas ventiladas opacas en clima tropical húmedo con el diseño de algunos sistemas de fachadas ventiladas opacas presentadas en Rubiano (2015, p. 113), donde tales sistemas han sido evaluados con simulaciones ambientales y calibradas a través de un prototipo en las diversas etapas de la investigación, lo que permite la comparación de datos y la identificación de comportamiento en términos de confort térmico.

Así, la primera etapa de la investigación partió de una caracterización y diagnóstico ambiental del área de estudio (Girardot, Colombia), seguida de la identificación del estado del arte en términos funcionales y de diseño para envolventes arquitectónicas de bajo impacto ambiental, teniendo en consideración tecnologías y estructuras para envolventes. Esto permitió el desarrollo de los primeros modelos de envolventes doble capa con especies vegetales bajo una exploración de diseño paramétrico con herramientas digitales como Grasshopper y simulaciones de confort como Ecotect $\AA^{\circledR}$ y Design Builder ${ }^{\circledR}$, publicado en Velasco y Robles (2011, p. 542). El uso de especies vegetales es considerado debido a que según Stec, Paassen y Maziarz (2005, p. 419), las plantas tienen la capacidad de disipar la radiación solar, y la transferencia de calor es más baja que la transferencia producida por las persianas, además de tener beneficios adicionales como mejorar el aislamiento térmico y la reducción del ruido por la absorción y reflexión del sonido.

La segunda etapa evolucionó hacia la verificación in situ de la compatibilidad de especies vegetales autóctonas (Bolaños y Moscoso, 2011, p. 16), sistemas y modalidades de mediciones térmicas, el desarrollo de la estructura de soporte y componentes del sistema; además de verificar la influencia de los diferentes factores como flujo 
de aire, masa, coeficiente de transmisión térmica y presencia de agua en el confort térmico, y así definir estrategias en favor de la reducción del impacto ambiental de los componentes del sistema en el ciclo de vida.

La tercera etapa adelantó la construcción del prototipo en Girardot para la medición de temperaturas con un sistema de fachada que comprende muros, puertas y ventanas en PVC (Rubiano, 2015, p. 113) y Varini (2013), con el registro de comportamientos en superficies internas. Los resultados de las mediciones realizadas entre octubre y diciembre de 2012 fueron comparados con las simulaciones ambientales realizadas en el software Design Builder ${ }^{\circledR}$, a fin de evaluar las discrepancias entre simulaciones y experimentación ya que, como menciona Jentsch, Bahaj y James (2008, p. 2148), los archivos de datos climáticos para simulación podrían no considerar los impactos potenciales del cambio climático, ni los riesgos de sobrecalentamiento local. Por tanto, una etapa posterior a la aquí presentada prevé el desarrollo de una herramienta de visualización de datos climáticos que facilite la comprensión de las particularidades del clima tropical húmedo, a fin de ayudar en la toma de decisiones y en el diseño de edificaciones que aumenten el confort térmico.

El desempeño térmico resultado de la etapa anterior sugirió la necesidad de una estrategia para la disminución de temperaturas al interior de la edificación, razón por la cual se diseñaron tres tipos de fachada: la primera ventilada opaca, la segunda con el uso de parasoles, y la tercera utilizando estrategias de masa térmica. Sobre estos diseños se realizaron simulaciones ambientales, asumiendo condiciones base del prototipo construido, lo que permitió reconocer el desempeño de las fachadas ventiladas en comparación con otras estrategias en clima cálido húmedo, particularmente para bajas latitudes y humedad media como Girardot.

De esta manera, este artículo tiene como fin presentar los resultados de la última etapa de la investigación, considerando la comparación entre simulaciones ambientales frente a las mediciones en sitio, y el desempeño de tres sistemas de fachadas opacas para la disminución de la temperatura al interior de la edificación en clima tropical húmedo.

\section{Metodología}

El trabajo contempló tres fases de desarrollo; la primera implicó la realización de simulaciones digitales de sistemas de fachada para definir la viabilidad de materiales y estrategias generales para confort en Girardot, la segunda involucró la construcción de un edificio en sitio para realizar mediciones del comportamiento real de la estructura a fin de calibrar modelos digitales de simulación, y, finalmente, la tercera fase impli- có la realización de simulaciones finales para tres tipos diversos de fachada con el ánimo de generar información aplicable en el contexto de la construcción local.

\section{Simulaciones y estudios previos}

De acuerdo con lo expuesto en Velasco y Robles (2011, p. 541), un análisis previo para climas como el de Girardot demuestra que el uso de estrategias pasivas puede llegar a subir los porcentajes de confort percibido desde un 5 a un $65 \%$ en promedio anual. En ese sentido, además de la ventilación natural, es de suma importancia evitar las ganancias de calor utilizando elementos de control solar, y en las zonas con temperaturas nocturnas menores, es útil el uso de masa térmica en fachadas, así como ventilación nocturna.

Teniendo en cuenta lo anterior, y con el ánimo de evaluar diversos tipos de fachadas ventiladas para este clima, se realizaron 66 simulaciones digitales organizadas dentro de cinco grupos generales, a saber: modelos con muro sencillo multicapa sin cámara de aire, muro sencillo multicapa con cámara de aire, muro doble con protección solar en los costados de mayor exposición oriente-occidente y zenit, con cámara de aire; muro sencillo multicapa ventilada, y muro doble con protección solar en los costados de mayor exposición oriente-occidente y zenit con ventilación (Figura 1).

Para las simulaciones se modeló un edificio de $3 \times 3 \times 3 \mathrm{~m}$, cubierto exclusivamente en las caras superior, oriental y occidental, mediante las configuraciones descritas en la Tabla 1.

\section{Medición de prototipo en sitio para calibración de simulaciones}

Para las mediciones en sitio se construyó una

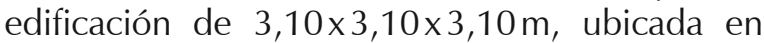
Girardot, Cundinamarca, con latitud $4^{\circ} 18^{\prime} 4.19^{\prime \prime} \mathrm{N}$ y longitud $74^{\circ} 48^{\prime} 40.32^{\prime \prime} \mathrm{O}$, en la sede de la Universidad Piloto de Colombia, Seccional Magdalena. La construcción está situada a nivel de segundo piso y girada aproximadamente $30^{\circ}$ con relación a la malla vial de la ciudad, a fin de que las fachadas laterales estén dispuestas en sentido oriente y occidente, expuestas a la radiación solar directa, lo que permite probar el desempeño de los materiales en condiciones extremas.

El prototipo está conformado por superficies en PVC de $2 \mathrm{~mm}$, con una cámara de aire de $6 \mathrm{~cm}$ entre las superficies, con una ventana dispuesta en la fachada norte y una puerta en la fachada sur, y cubierta inclinada en drywall, no ventilada; además de unos parales metálicos sobre las fachadas oriente y occidente para la instalación de los diversos diseños de revestimiento.

Es allí donde se sitúan los cuatro termopares para la medición de las superficies interiores y exteriores con el objeto de identificar las diferencias de temperatura entre estas, además de un termopar en el centro del espacio para calcular la 

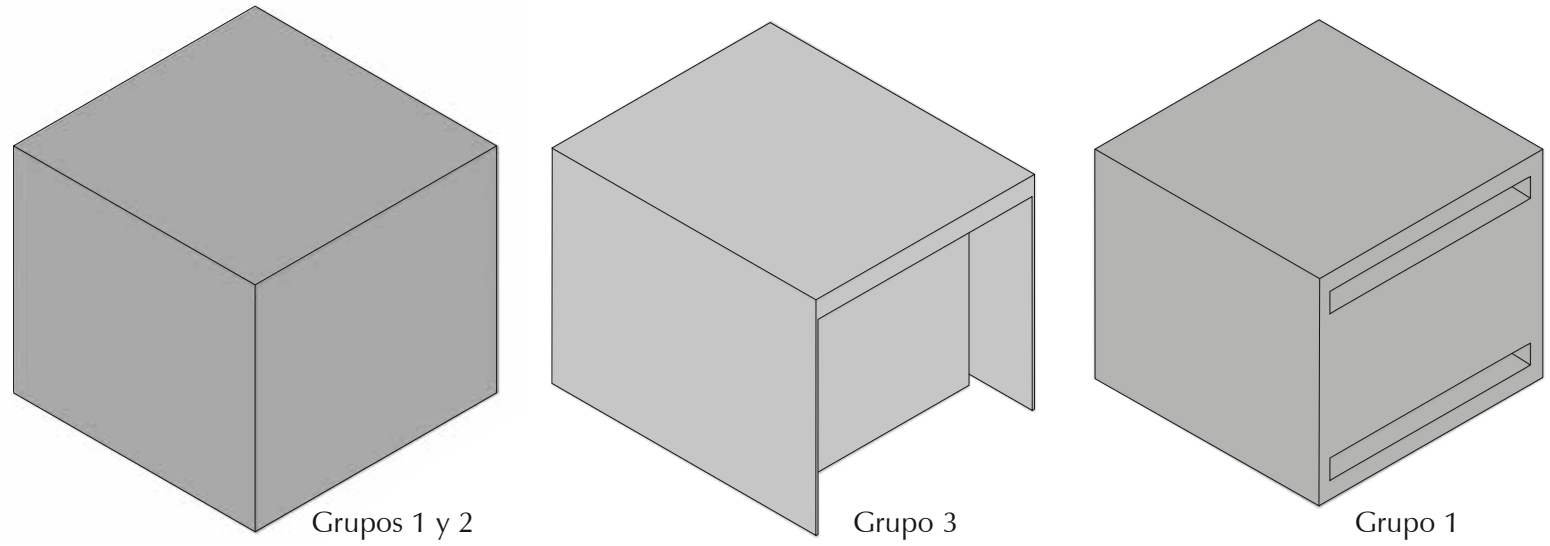

\section{Modelos con muro sencillo multicapa sin cámara de aire}

\begin{tabular}{|c|c|c|c|c|c|}
\hline № de modelo & Materiales & Co & osición & & Operación \\
\hline \multirow{2}{*}{1} & \multirow{2}{*}{ Enredadera } & Polietileno alta densidad & $1 \mathrm{~mm}$ & Capa interna & \multirow{41}{*}{$\begin{array}{c}\text { Sin } \\
\text { ventilación }\end{array}$} \\
\hline & & Corcho & $1 \mathrm{~mm}$ & Capa externa & \\
\hline \multirow{3}{*}{2} & \multirow{3}{*}{ Bolsillos } & Ceramic tiles & $2 \mathrm{~cm}$ & Capa interna & \\
\hline & & Tierra & $10 \mathrm{~cm}$ & & \\
\hline & & Corcho & $1 \mathrm{~mm}$ & Capa externa & \\
\hline \multirow{3}{*}{3} & \multirow{3}{*}{ Paneles verdes } & Polietileno alta densidad & $3 \mathrm{~mm}$ & Capa interna & \\
\hline & & $\begin{array}{c}\text { Tierra } \\
\ldots\end{array}$ & $15 \mathrm{~cm}$ & & \\
\hline & & Corcho & $1 \mathrm{~mm}$ & Capa externa & \\
\hline \multirow{3}{*}{4} & \multirow{3}{*}{ Mampostería } & Pañete & $1,5 \mathrm{~cm}$ & Capa interna & \\
\hline & & Ladrillo & $12 \mathrm{~cm}$ & & \\
\hline & & Pañete & $1,5 \mathrm{~cm}$ & Capa externa & \\
\hline \multirow{2}{*}{5} & \multirow{2}{*}{$\begin{array}{c}\text { Mampostería a } \\
\text { la vista }\end{array}$} & Pañete & $1,5 \mathrm{~cm}$ & Capa interna & \\
\hline & & Ladrillo & $12 \mathrm{~cm}$ & Capa externa & \\
\hline \multirow{3}{*}{6} & \multirow{3}{*}{ Bloque № 5} & Pañete & $1,5 \mathrm{~cm}$ & Capa interna & \\
\hline & & Bloque $N^{\circ} 5$ & $10 \mathrm{~cm}$ & & \\
\hline & & Pañete & $1,5 \mathrm{~cm}$ & Capa externa & \\
\hline 7 & Madera & Madera pino & $2,5 \mathrm{~cm}$ & Única capa & \\
\hline 8 & Tableta & Clay tile & $1 \mathrm{~cm}$ & Única capa & \\
\hline 9 & Fibrocemento & Fibrocemento & $16 \mathrm{~mm}$ & Única capa & \\
\hline 10 & Vidrio & Vidrio & $4 \mathrm{~cm}$ & Única capa & \\
\hline \multirow{4}{*}{11} & \multirow{4}{*}{ Madera } & Pañete & $1,5 \mathrm{~cm}$ & Capa interna & \\
\hline & & Ladrillo & $12 \mathrm{~cm}$ & & \\
\hline & & Pañete & $1,5 \mathrm{~cm}$ & & \\
\hline & & Madera pino & $3 \mathrm{~cm}$ & Capa externa & \\
\hline \multirow{4}{*}{12} & \multirow{4}{*}{ Tableta } & Pañete & $1,5 \mathrm{~cm}$ & Capa interna & \\
\hline & & Ladrillo & $12 \mathrm{~cm}$ & & \\
\hline & & Pañete & $1,5 \mathrm{~cm}$ & & \\
\hline & & clay tile & $1 \mathrm{~cm}$ & Única capa & \\
\hline \multirow{4}{*}{13} & \multirow{4}{*}{ Fibrocemento } & Pañete & $1,5 \mathrm{~cm}$ & Capa interna & \\
\hline & & Ladrillo & $12 \mathrm{~cm}$ & & \\
\hline & & Pañete & $1,5 \mathrm{~cm}$ & & \\
\hline & & Fibrocemento & $16 \mathrm{~mm}$ & Única capa & \\
\hline \multirow{3}{*}{14} & \multirow{3}{*}{ PVC-Concreto } & PVC & $2 \mathrm{~mm}$ & Capa interna & \\
\hline & & Concreto & $10 \mathrm{~cm}$ & & \\
\hline & & PVC & $2 \mathrm{~mm}$ & Capa externa & \\
\hline \multirow{3}{*}{15} & \multirow{3}{*}{ PVC-Poliuretano } & PVC & $2 \mathrm{~mm}$ & Capa interna & \\
\hline & & Poliuretano & $10 \mathrm{~cm}$ & & \\
\hline & & PVC & $2 \mathrm{~mm}$ & Capa externa & \\
\hline \multirow{3}{*}{16} & \multirow{3}{*}{ PVC-Tierra } & PVC & $2 \mathrm{~mm}$ & Capa interna & \\
\hline & & Tierra & $10 \mathrm{~cm}$ & & \\
\hline & & PVC & $2 \mathrm{~mm}$ & Capa externa & \\
\hline
\end{tabular}

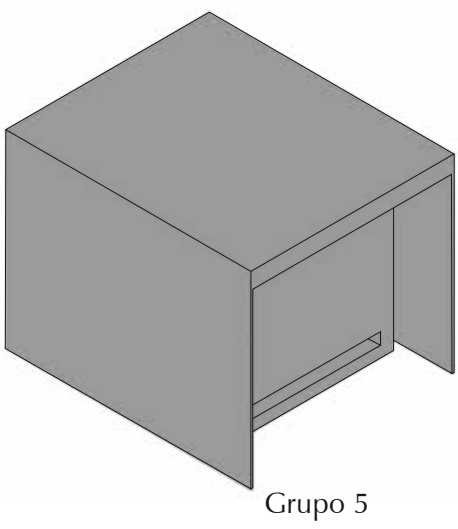

(A) Figura 1. Esquema de las configuraciones de modelos de simulaciones según grupos Fuente: elaboración propia, 2017.
- Tabla 1. Configuraciones de los modelos de simulación con muro sencillo multicapa sin cámara de aire Fuente: elaboración propia, 2013. 
Modelos con muro sencillo multicapa con cámara de aire

\begin{tabular}{|c|c|c|c|c|c|}
\hline $\begin{array}{l}\text { No de } \\
\text { modelo }\end{array}$ & Materiales & & osición & & Operación \\
\hline \multirow{3}{*}{17} & \multirow{3}{*}{ Madera doble } & Madera pino & $2,5 \mathrm{~cm}$ & Capa interna & \multirow{3}{*}{ Off } \\
\hline & & Airgap & $12 \mathrm{~cm}$ & & \\
\hline & & Madera pino & $3 \mathrm{~cm}$ & Capa externa & \\
\hline \multirow{6}{*}{18} & \multirow{6}{*}{ Enredadera } & Pañete & $1,5 \mathrm{~cm}$ & Capa interna & \multirow{6}{*}{ Off } \\
\hline & & Ladrillo & $12 \mathrm{~cm}$ & & \\
\hline & & Pañete & $1,5 \mathrm{~cm}$ & & \\
\hline & & Polietileno alta densidad & $5 \mathrm{~mm}$ & & \\
\hline & & Airgap & $75 \mathrm{~mm}$ & & \\
\hline & & Corcho & $1 \mathrm{~mm}$ & Capa externa & \\
\hline \multirow{7}{*}{19} & \multirow{7}{*}{ Bolsillos } & Pañete & $1,5 \mathrm{~cm}$ & Capa interna & \multirow{7}{*}{ Off } \\
\hline & & Ladrillo & $12 \mathrm{~cm}$ & & \\
\hline & & Pañete & $1,5 \mathrm{~cm}$ & & \\
\hline & & Ceramic tiles & $1 \mathrm{~cm}$ & & \\
\hline & & Tierra & $20 \mathrm{~cm}$ & & \\
\hline & & Airgap & $75 \mathrm{~mm}$ & & \\
\hline & & Corcho & $1 \mathrm{~mm}$ & Capa externa & \\
\hline \multirow{7}{*}{20} & \multirow{7}{*}{ Paneles verdes } & Pañete & $1,5 \mathrm{~cm}$ & Capa interna & \multirow{7}{*}{ Off } \\
\hline & & Ladrillo & $12 \mathrm{~cm}$ & & \\
\hline & & Pañete & $1,5 \mathrm{~cm}$ & & \\
\hline & & Polietileno alta densidad & $3 \mathrm{~mm}$ & & \\
\hline & & Tierra & $15 \mathrm{~cm}$ & & \\
\hline & & Airgap & $75 \mathrm{~mm}$ & & \\
\hline & & Corcho & $1 \mathrm{~mm}$ & Capa externa & \\
\hline \multirow{3}{*}{21} & \multirow{3}{*}{ PVC } & PVC & $2 \mathrm{~mm}$ & Capa interna & \multirow{3}{*}{ Off } \\
\hline & & Airgap & $10 \mathrm{~cm}$ & & \\
\hline & & PVC & $2 \mathrm{~mm}$ & Capa externa & \\
\hline \multirow{5}{*}{22} & \multirow{5}{*}{$\begin{array}{l}\text { PVC compuesto de } \\
\text { aire }\end{array}$} & PVC & $3 \mathrm{~mm}$ & Capa interna & \multirow{5}{*}{ Off } \\
\hline & & Airgap & $20 \mathrm{~cm}$ & & \\
\hline & & PVC & $2 \mathrm{~mm}$ & & \\
\hline & & Airgap & $10 \mathrm{~cm}$ & & \\
\hline & & PVC & $2 \mathrm{~mm}$ & Capa externa & \\
\hline & & PVC & $3 \mathrm{~mm}$ & Capa interna & \\
\hline & & Airgap & $20 \mathrm{~cm}$ & & \\
\hline 23 & PV compuesto de & PVC & $2 \mathrm{~mm}$ & & Off \\
\hline & & Perlita & $10 \mathrm{~cm}$ & & \\
\hline & & PVC & $2 \mathrm{~mm}$ & Capa externa & \\
\hline & & PVC & $3 \mathrm{~mm}$ & Capa interna & \\
\hline & & Airgap & $20 \mathrm{~cm}$ & & \\
\hline 24 & $\begin{array}{l}\text { PVC compuesto de } \\
\text { leca }\end{array}$ & PVC & $2 \mathrm{~mm}$ & & Off \\
\hline & & Leca & $10 \mathrm{~cm}$ & & \\
\hline & & PVC & $2 \mathrm{~mm}$ & Capa externa & \\
\hline & & PVC & $3 \mathrm{~mm}$ & Capa interna & \\
\hline & & Airgap & $20 \mathrm{~cm}$ & & \\
\hline 25 & $\begin{array}{c}\text { PVC compuesto de } \\
\text { tierra }\end{array}$ & PVC & $2 \mathrm{~mm}$ & & Off \\
\hline & & Tierra & $10 \mathrm{~cm}$ & & \\
\hline & & PVC & $2 \mathrm{~mm}$ & Capa externa & \\
\hline & & PVC & $3 \mathrm{~mm}$ & Capa interna & \\
\hline & & Airgap & $20 \mathrm{~cm}$ & & \\
\hline 26 & PVC compuesto de & PVC & $2 \mathrm{~mm}$ & & Off \\
\hline & & Concreto & $10 \mathrm{~cm}$ & & \\
\hline & & PVC & $2 \mathrm{~mm}$ & Capa externa & \\
\hline & & PVC & $3 \mathrm{~mm}$ & Capa interna & \\
\hline & PVC compuesto de & Airgap & $20 \mathrm{~cm}$ & & \\
\hline 27 & $\begin{array}{l}\text { leca abertura 30\% } \\
\text { vent. sin operación }\end{array}$ & PVC & $2 \mathrm{~mm}$ & & Off \\
\hline & nocturna & Leca & $10 \mathrm{~cm}$ & & \\
\hline & & PVC & $2 \mathrm{~mm}$ & Capa externa & \\
\hline
\end{tabular}

Tabla 2. Configuraciones de los modelos de simulación con muro sencillo multicapa con cámara de aire

Fuente: elaboración propia, 2013. 
Modelos con muro doble con protección solar en los costados de mayor exposición oriente-occidente y zenit, con cámara de aire

\begin{tabular}{|c|c|c|c|c|}
\hline $\begin{array}{l}\text { № de } \\
\text { modelo }\end{array}$ & Materiales & \multicolumn{2}{|c|}{ Composición } & Operación \\
\hline \multirow{10}{*}{28} & \multirow{7}{*}{$\begin{array}{c}\text { Ext: Enre- } \\
\text { dadera -Int: } \\
\text { Mamp } 12 \mathrm{~cm} \\
+ \text { Madera } 5 \\
\mathrm{~cm}\end{array}$} & Madera pino & Capa interna & \multirow{10}{*}{ Off } \\
\hline & & Ladrillo & $12 \mathrm{~cm}$ & \\
\hline & & Madera pino & $2,5 \mathrm{~cm}$ & \\
\hline & & Espacio de separación entre & ento de protección solar $(15 \mathrm{~cm})$ & \\
\hline & & Polietileno alta densidad & $5 \mathrm{~mm}$ & \\
\hline & & Аirgap & $75 \mathrm{~mm}$ & \\
\hline & & Corcho & Capa externa & \\
\hline & \multirow{3}{*}{$\begin{array}{l}\text { Ext: Enre- } \\
\text { dadera-Int: }\end{array}$} & Madera pino & Capa interna & \\
\hline & & Ladrillo & $24 \mathrm{~cm}$ & \\
\hline & & Madera pino & Capa externa & \\
\hline
\end{tabular}

Mamp $24 \mathrm{~cm}$ Espacio de separación entre muro y elemento de protección solar $(15 \mathrm{~cm})$

+ Madera $\quad$ Polietileno alta densidad $\quad 5 \mathrm{~mm} \quad$ Capa interna

$5 \mathrm{~cm}$

Airgap $75 \mathrm{~mm}$

Corcho $\quad \ldots . . . . . . \ldots \ldots \ldots . .1 \mathrm{~mm} \quad$ Capa externa

Madera pino $\quad 2,5 \mathrm{~cm} \quad$ Capa interna

Ext: Panel

$12 \mathrm{~cm}$

verde-Int: Madera pino $\quad 2,5 \mathrm{~cm} \quad$ Capa externa

30 Mamp $12 \mathrm{~cm}$ Espacio de separación entre muro y elemento de protección solar $(15 \mathrm{~cm})$
+ Madera
Polietileno alta densidad
$3 \mathrm{~mm}$
Capa interna

$5 \mathrm{~cm}$

Tierra $\quad 15 \mathrm{~cm}$

Airgap $75 \mathrm{~mm}$

Madera Pino 2,5cm

Ext: Panel

verde-Int:

$2,5 \mathrm{~cm}$

Ladrillo

$2,5 \mathrm{~cm}$

Capa interna

Madera Pino

Capa externa

31 Mamp $24 \mathrm{~cm}$ Espacio de separación entre muro y elemento de protección solar $(15 \mathrm{~cm})$

$\begin{array}{llll}+ \text { Madera } & \text { Polietileno alta densidad } & 3 \mathrm{~mm} & \text { Capa interna }\end{array}$

$15 \mathrm{~cm}$

Airgap $75 \mathrm{~mm}$

Madera pino $2,5 \mathrm{~cm}$

Ladrillo

$2,5 \mathrm{~cm} \quad$ Capa interna

Ext: Bol-

Madera pino

$12 \mathrm{~cm}$

$2,5 \mathrm{~cm} \quad$ Capa externa

32

silos-Int:

Off

$5 \mathrm{~cm}$

Ceramic tiles

Airgap $75 \mathrm{~mm}$

Madera pino $\quad 2,5 \mathrm{~cm}$

Ladrillo $24 \mathrm{~cm}$

Ext: Bol-

sillos-Int:

Madera pino $\quad 2,5 \mathrm{~cm}$

Capa interna

Off

33

Espacio de separación entre muro y elemento de protección solar $(15 \mathrm{~cm})$

+ Madera $\quad$ Ceramic tiles $\quad 1 \mathrm{~cm}$ Capa interna

$5 \mathrm{~cm}$

$20 \mathrm{~cm}$

Airgap $75 \mathrm{~mm}$

Pañete $1,5 \mathrm{~cm}$

Ladrillo

$\begin{array}{ll}\text { Ext: Mamp } & \text { Pañete } \\ 15 \mathrm{~cm}-\text { Int: } & \text { Espacio de separación entre muro y elemento de protección solar }(15 \mathrm{~cm})\end{array}$

Espacio de separació

$1,5 \mathrm{~cm}$

Ladrillo $12 \mathrm{~cm}$

Pañete $1,5 \mathrm{~cm}$

Pañete $1,5 \mathrm{~cm}$

Ladrillo $24 \mathrm{~cm}$

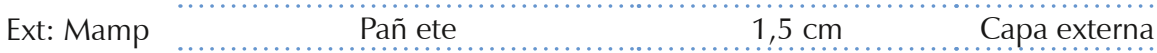

$3515 \mathrm{~cm}$-Int: Espacio de separación entre muro y elemento de protección solar $(15 \mathrm{~cm})$

Mamp $27 \mathrm{~cm}$ Pañete $1,5 \mathrm{~cm}$ Capa interna

Ladrillo $\ldots \ldots \ldots$

Pañete $\quad 1,5 \mathrm{~cm} \quad$ Capa externa

Madera pino $2,5 \mathrm{~cm}$ Capa interna

Ladrillo ..................... $12 \mathrm{~cm}$

Madera pino $\quad 2,5 \mathrm{~cm} \quad$ Capa externa

36 Mamp 12 cm Espacio de separación entre muro y elemento de protección solar $(15 \mathrm{~cm})$

Madera
$5 \mathrm{~cm}$$\quad$ Pañete $\quad 1,5 \mathrm{~cm} \quad 12 \mathrm{~cm}$ Capa interna

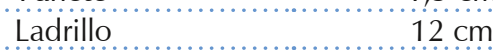

Pañete $\quad 1,5 \mathrm{~cm} \quad$ Capa externa

Off

Off

Off

Off 


\begin{tabular}{|c|c|c|c|c|c|}
\hline \multirow{7}{*}{37} & \multirow{7}{*}{$\begin{array}{l}\text { Ext: Mamp } \\
15 \mathrm{~cm}-\mathrm{Int}: \\
\text { Mamp } 24 \mathrm{~cm} \\
+ \text { Madera } \\
5 \mathrm{~cm}\end{array}$} & Madera Pino & $2,5 \mathrm{~cm}$ & Capa interna & \multirow{7}{*}{ Off } \\
\hline & & Ladrillo & $24 \mathrm{~cm}$ & & \\
\hline & & Madera Pino & $2,5 \mathrm{~cm}$ & Capa externa & \\
\hline & & \multicolumn{3}{|c|}{ Espacio de separación entre muro y elemento de protección solar $(15 \mathrm{~cm})$} & \\
\hline & & Pañete . . . . . . . . & $1,5 \mathrm{~cm}$ & Capa interna & \\
\hline & & Ladrillo & $12 \mathrm{~cm}$ & & \\
\hline & & Pañete & $1,5 \mathrm{~cm}$ & Capa externa & \\
\hline \multirow{5}{*}{38} & \multirow{5}{*}{$\begin{array}{l}\text { Ext: Mamp } \\
3 \mathrm{~cm}-1 \mathrm{lnt}: \\
\text { Mamp } 15 \mathrm{~cm}\end{array}$} & Pañete & $1,5 \mathrm{~cm}$ & Capa interna & \multirow{5}{*}{ Of } \\
\hline & & Ladrillo & $12 \mathrm{~cm}$ & & \\
\hline & & Pañete & $1,5 \mathrm{~cm}$ & Capa externa & \\
\hline & & \multicolumn{3}{|c|}{ Espacio de separación entre muro y elemento de protección solar $(15 \mathrm{~cm})$} & \\
\hline & & Ladrillo & $3 \mathrm{~cm}$ & Única capa & \\
\hline \multirow{5}{*}{39} & \multirow{5}{*}{$\begin{array}{c}\text { Ext: Cerámica } \\
4 \mathrm{~cm}-\text { Int: } \\
\text { Mamp } 24 \mathrm{~cm} \\
+ \text { Madera } \\
5 \mathrm{~cm}\end{array}$} & Madera pino & $2,5 \mathrm{~cm}$ & Capa interna & \multirow{5}{*}{ Of } \\
\hline & & Ladrillo & $24 \mathrm{~cm}$ & & \\
\hline & & Madera pino & $2,5 \mathrm{~cm}$ & Capa externa & \\
\hline & & \multicolumn{3}{|c|}{ Espacio de separación entre muro y elemento de protección solar $(15 \mathrm{~cm})$} & \\
\hline & & Ceramica & $4 \mathrm{~cm}$ & Única capa & \\
\hline \multirow{7}{*}{40} & \multirow{7}{*}{$\begin{array}{c}\text { Ext: Cerámica } \\
4 \text { cm-Int: } \\
\text { Mamp12 } \\
\text { cm + airgap } \\
12 \text { cm } \\
\text { Madera } 2,5 \\
\text { cm }\end{array}$} & Pañete & $1,5 \mathrm{~cm}$ & Capa interna & \multirow{7}{*}{ Of } \\
\hline & & Ladrillo & $6 \mathrm{~cm}$ & & \\
\hline & & Airgap & $12 \mathrm{~cm}$ & & \\
\hline & & Ladrillo & $6 \mathrm{~cm}$ & & \\
\hline & & Madera pino & $2,5 \mathrm{~cm}$ & Capa externa & \\
\hline & & \multicolumn{3}{|c|}{ Espacio de separación entre muro y elemento de protección solar $(15 \mathrm{~cm})$} & \\
\hline & & Cerámica & $4 \mathrm{~cm}$ & Única capa & \\
\hline \multirow{5}{*}{41} & & Pañete & $1,5 \mathrm{~cm}$ & Capa interna & \\
\hline & $\begin{array}{l}\text { Ext: Cerámica } \\
4 \mathrm{~cm}-\ln t:\end{array}$ & Termoarcilla & $24 \mathrm{~cm}$ & & \\
\hline & $\begin{array}{l}\text { Termoarcilla } \\
24 \mathrm{~cm}+\end{array}$ & Madera Pino & $2,5 \mathrm{~cm}$ & Capa externa & Off \\
\hline & Madera 2,5 & Espacio de separación entre m & ento de $p$ & in solar $(15 \mathrm{~cm})$ & \\
\hline & & Cerámica & $4 \mathrm{~cm}$ & Única capa & \\
\hline & & Pañete & $1,5 \mathrm{~cm}$ & Capa interna & \\
\hline & & Mampostería & $12 \mathrm{~cm}$ & & \\
\hline & & Pañete & $1,5 \mathrm{~cm}$ & Capa externa & \\
\hline 42 & Mampostería & Espacio de separación entre m & ento de $p$ & in solar $(15 \mathrm{~cm})$ & Off \\
\hline & & PVC & $2 \mathrm{~mm}$ & Capa interna & \\
\hline & & Airgap & $10 \mathrm{~cm}$ & & \\
\hline & & PVC & $2 \mathrm{~mm}$ & Capa externa & \\
\hline & & PVC & $2 \mathrm{~mm}$ & Capa interna & \\
\hline & & Airgap & $10 \mathrm{~cm}$ & & \\
\hline & & PVC & $2 \mathrm{~mm}$ & Capa externa & \\
\hline 43 & Int PVC Ext & Espacio de separación entre m & ento de $p$ & in solar $(15 \mathrm{~cm})$ & Off \\
\hline & & PVC & $2 \mathrm{~mm}$ & Capa interna & \\
\hline & & Airgap & $10 \mathrm{~mm}$ & & \\
\hline & & PVC & $2 \mathrm{~mm}$ & Capa externa & \\
\hline & & Madera pino & $2,5 \mathrm{~cm}$ & Capa interna & \\
\hline & & PVC & $2 \mathrm{~mm}$ & & \\
\hline & $\begin{array}{l}\text { Int PVCMa- } \\
\text { dera } 2,5 \mathrm{~cm}\end{array}$ & Airgap & $10 \mathrm{~cm}$ & & \\
\hline 44 & $\begin{array}{l}\text { Ext Madera } \\
2,5 \mathrm{~cm}\end{array}$ & PVC & $2 \mathrm{~mm}$ & Capa externa & Off \\
\hline & & Espacio de separación entre my & ento de $p$ & in solar $(15 \mathrm{~cm})$ & \\
\hline & & Madera pino & $2,5 \mathrm{~cm}$ & Única capa & \\
\hline & & Madera pino & $2,5 \mathrm{~cm}$ & Capa interna & \\
\hline & & PVC & $2 \mathrm{~mm}$ & & \\
\hline & & airgap & $10 \mathrm{~cm}$ & & \\
\hline & Int PVC & PVC & $2 \mathrm{~mm}$ & Capa externa & \\
\hline 45 & $\begin{array}{l}\text { Madera 2,5 } \\
\text { cm Ext Panel }\end{array}$ & Espacio de separación entre m & ento de $p$ & n solar $(15 \mathrm{~cm})$ & Off \\
\hline & verde & Polietileno de alta densidad & $3 \mathrm{~mm}$ & Capa Interna & \\
\hline & & Tierra & $15 \mathrm{~cm}$ & & \\
\hline & & Airgap & $75 \mathrm{~mm}$ & & \\
\hline & & Corcho & $1 \mathrm{~mm}$ & Capa externa & \\
\hline
\end{tabular}

(4) Tabla 3. Configuraciones de los modelos de simulación con muro doble con protección solar en los costados de mayor exposición oriente-occidente y zenit, con cámara de aire

Fuente: elaboración propia, 2013. 
Luciani-Mejía, S., Velasco-Gómez, R., \& Hudson, R. (2018). Ecoenvolventes: análisis del uso de fachadas ventiladas en clima cálido-húmedo. Revista de Arquitectura (Bogotá), 20(2), 62-77. Doi: http://dx.doi.org/I0. I47I8/RevArq.20 I8.20.2. 1726

\section{Modelos con muro sencillo multicapa ventilada}

\begin{tabular}{|c|c|c|c|c|c|}
\hline $\begin{array}{l}\text { № de } \\
\text { modelo }\end{array}$ & Materiales & \multicolumn{3}{|c|}{ Composición } & Operación \\
\hline \multirow{3}{*}{46} & \multirow{3}{*}{ Mampostería 15 cm - ventilación inferior - 3,8\% } & Pañete & $1,5 \mathrm{~cm}$ & Capa interna & \multirow{3}{*}{ On } \\
\hline & & Ladrillo & $12 \mathrm{~cm}$ & & \\
\hline & & Pañete & $1,5 \mathrm{~cm}$ & Capa externa & \\
\hline \multirow{3}{*}{47} & \multirow{3}{*}{$\begin{array}{c}\text { Mampostería } 15 \text { cm - ventilación superior - } \\
\text { 3,8\% }\end{array}$} & Pañete & $1,5 \mathrm{~cm}$ & Capa interna & \multirow{3}{*}{ On } \\
\hline & & Ladrillo & $12 \mathrm{~cm}$ & & \\
\hline & & Pañete & $1,5 \mathrm{~cm}$ & Capa externa & \\
\hline \multirow{3}{*}{48} & \multirow{3}{*}{$\begin{array}{l}\text { Mampostería } 15 \text { cm - ventilación } \\
\text { superior 3,8\% - inferior 3,8\% }\end{array}$} & Pañete & $1,5 \mathrm{~cm}$ & Capa interna & \multirow{3}{*}{ On } \\
\hline & & Ladrillo & $12 \mathrm{~cm}$ & & \\
\hline & & Pañete & $1,5 \mathrm{~cm}$ & Capa externa & \\
\hline \multirow{3}{*}{49} & \multirow{3}{*}{ Mampostería 15 cm - puerta-ventana } & Pañete & $1,5 \mathrm{~cm}$ & Capa interna & \multirow{3}{*}{ On } \\
\hline & & Ladrillo & $12 \mathrm{~cm}$ & & \\
\hline & & Pañete & $1,5 \mathrm{~cm}$ & capa externa & \\
\hline \multirow{3}{*}{50} & \multirow{3}{*}{ Mampostería 15 cm - puerta-ventana } & Pañete & $1,5 \mathrm{~cm}$ & capa interna & \multirow{3}{*}{ On } \\
\hline & & Ladrillo & $12 \mathrm{~cm}$ & & \\
\hline & & Pañete & $1,5 \mathrm{~cm}$ & Capa externa & \\
\hline \multirow{3}{*}{51} & \multirow{3}{*}{ Cubo Básico 6,6\% superior - 6,6\% inferior } & Pañete & $1,5 \mathrm{~cm}$ & Capa interna & \multirow{3}{*}{ On } \\
\hline & & Ladrillo & $12 \mathrm{~cm}$ & & \\
\hline & & Pañete & $1,5 \mathrm{~cm}$ & Capa externa & \\
\hline \multirow{3}{*}{52} & & Pañete & $1,5 \mathrm{~cm}$ & Capa interna & \\
\hline & Cubo Básico 33\% superior - 33\% inferior & Ladrillo & $12 \mathrm{~cm}$ & & On \\
\hline & & Pañete & $1,5 \mathrm{~cm}$ & Capa externa & \\
\hline & & Pañete & $1,5 \mathrm{~cm}$ & Capa interna & \\
\hline 53 & Cubo Básico 66\% superior - 66\% inferior & Ladrillo & $12 \mathrm{~cm}$ & & On \\
\hline & & Pañete & $1,5 \mathrm{~cm}$ & capa externa & \\
\hline & & Pañete & $1,5 \mathrm{~cm}$ & Capa interna & \\
\hline 54 & Cubo Básico 100\% superficie & Ladrillo & $12 \mathrm{~cm}$ & & On \\
\hline & & Pañete & $1,5 \mathrm{~cm}$ & Capa externa & \\
\hline & & PVC & $3 \mathrm{~mm}$ & Capa interna & \\
\hline & & Airgap & $20 \mathrm{~cm}$ & & $22: 00$ \\
\hline 55 & PVC compuesto de Leca abertura 30\% vent. & PVC & $2 \mathrm{~mm}$ & & $\mathrm{a}$ \\
\hline & & Leca & $10 \mathrm{~cm}$ & & 7:00 \\
\hline & & PVC & $2 \mathrm{~mm}$ & Capa externa & \\
\hline & & PVC & $3 \mathrm{~mm}$ & Capa interna & \\
\hline & & Airgap & $20 \mathrm{~cm}$ & & $22: 00$ \\
\hline 56 & $\begin{array}{l}\text { PVC compuesto de Leca abertura } 30 \% \text { - } \\
\text { ventana sin operación nocturna }\end{array}$ & PVC & $2 \mathrm{~mm}$ & & $\mathrm{a}$ \\
\hline & & Leca & $10 \mathrm{~cm}$ & & 7:00 \\
\hline & & PVC & $2 \mathrm{~mm}$ & Capa externa & \\
\hline & & PVC & $3 \mathrm{~mm}$ & Capa interna & \\
\hline & & Airgap & $20 \mathrm{~cm}$ & & $22: 00$ \\
\hline 57 & $\begin{array}{l}\text { PVC compuesto de Leca abertura 30\% - } \\
\text { ventana con operación nocturna }\end{array}$ & PVC & $2 \mathrm{~mm}$ & & $\mathrm{a}$ \\
\hline & & Leca & $10 \mathrm{~cm}$ & & 7:00 \\
\hline & & PVC & $2 \mathrm{~mm}$ & Capa externa & \\
\hline & & PVC & $3 \mathrm{~mm}$ & Capa interna & \\
\hline & & Airgap & $20 \mathrm{~cm}$ & & $22: 00$ \\
\hline 58 & $\begin{array}{l}\text { PVC compuesto de Leca abertura 30\% - } \\
\text { ventana nocturna pantalla cerrando ventana }\end{array}$ & PVC & $2 \mathrm{~mm}$ & & $\mathrm{a}$ \\
\hline & & Leca & $10 \mathrm{~cm}$ & & $7: 00$ \\
\hline & & PVC & $2 \mathrm{~mm}$ & Capa externa & \\
\hline & & PVC & $3 \mathrm{~mm}$ & Capa interna & \\
\hline & & Airgap & $20 \mathrm{~cm}$ & & $22: 00$ \\
\hline 59 & $\begin{array}{c}\text { PVC compuesto de Leca abertura 15\% - } \\
\text { ventana nocturna }\end{array}$ & PVC & $2 \mathrm{~mm}$ & & $\mathrm{a}$ \\
\hline & & Leca & $10 \mathrm{~cm}$ & & $7: 00$ \\
\hline & & PVC & $2 \mathrm{~mm}$ & Capa externa & \\
\hline
\end{tabular}

Tabla 4. Configuraciones de los modelos de simulación con muro sencillo multicapa ventilada Fuente: elaboración propia, 2013. 
Modelos con muro doble con protección solar en los costados de mayor exposición oriente-occidente y zenit, con ventilación

\begin{tabular}{|c|c|c|c|c|c|}
\hline $\begin{array}{c}\text { No } \\
\text { demodelo }\end{array}$ & Materiales & & nposicić & & Operación \\
\hline \multirow{6}{*}{60} & \multirow{6}{*}{$\begin{array}{l}\text { Cerámica ventilación } \\
\text { hole } 0 \%\end{array}$} & Madera Pino & $2,5 \mathrm{~cm}$ & Capa interna & \multirow{6}{*}{ On } \\
\hline & & Ladrillo & $24 \mathrm{~cm}$ & & \\
\hline & & Airgap & $12 \mathrm{~cm}$ & & \\
\hline & & Madera Pino & $2,5 \mathrm{~cm}$ & Capa externa & \\
\hline & & \multicolumn{3}{|c|}{$\begin{array}{l}\text { Espacio de separación entre muro y elemento de protección } \\
\qquad \operatorname{solar}(15 \mathrm{~cm})\end{array}$} & \\
\hline & & Cerámica & $4 \mathrm{~cm}$ & Única capa & \\
\hline \multirow{6}{*}{61} & \multirow{6}{*}{$\begin{array}{l}\text { Cerámica ventilación } \\
\text { hole } \\
6,6 \% \text { inferior - } 6,6 \% \\
\text { superior }\end{array}$} & Madera Pino & $2,5 \mathrm{~cm}$ & Capa interna & \multirow{6}{*}{ On } \\
\hline & & Ladrillo & $24 \mathrm{~cm}$ & & \\
\hline & & Airgap & $12 \mathrm{~cm}$ & & \\
\hline & & Madera Pino & $2,5 \mathrm{~cm}$ & Capa externa & \\
\hline & & \multicolumn{3}{|c|}{$\begin{array}{l}\text { Espacio de separación entre muro y elemento de protección } \\
\qquad \operatorname{solar}(15 \mathrm{~cm})\end{array}$} & \\
\hline & & Cerámica & $4 \mathrm{~cm}$ & Única capa & \\
\hline \multirow{6}{*}{62} & \multirow{6}{*}{$\begin{array}{l}\text { Cerámica ventilación } \\
\text { hole } \\
\text { 33\% superior - 33\% } \\
\text { inferior }\end{array}$} & Madera Pino & $2,5 \mathrm{~cm}$ & Capa interna & \multirow{6}{*}{ On } \\
\hline & & Ladrillo & $24 \mathrm{~cm}$ & & \\
\hline & & Airgap & $12 \mathrm{~cm}$ & & \\
\hline & & Madera Pino & $2,5 \mathrm{~cm}$ & Capa externa & \\
\hline & & \multicolumn{3}{|c|}{$\begin{array}{l}\text { Espacio de separación entre muro y elemento de protección } \\
\operatorname{sol}(15 \mathrm{~cm})\end{array}$} & \\
\hline & & Cerámica & $4 \mathrm{~cm}$ & Única capa & \\
\hline \multirow{6}{*}{63} & \multirow{6}{*}{$\begin{array}{l}\text { Cerámica ventilación } \\
\text { hole } \\
66 \% \text { superior - } 66 \% \\
\text { inferior }\end{array}$} & Madera Pino & $2,5 \mathrm{~cm}$ & Capa interna & \multirow{6}{*}{ On } \\
\hline & & Ladrillo & $24 \mathrm{~cm}$ & & \\
\hline & & Airgap & $12 \mathrm{~cm}$ & & \\
\hline & & Madera Pino & $2,5 \mathrm{~cm}$ & Capa externa & \\
\hline & & \multicolumn{3}{|c|}{ 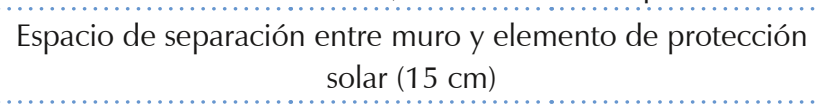 } & \\
\hline & & Cerámica & $4 \mathrm{~cm}$ & Única capa & \\
\hline \multirow{6}{*}{64} & \multirow{6}{*}{$\begin{array}{l}\text { Cerámica ventilación } \\
\text { hole } \\
100 \% \text { superficie }\end{array}$} & Madera Pino & $2,5 \mathrm{~cm}$ & Capa interna & \multirow{6}{*}{ On } \\
\hline & & Ladrillo & $24 \mathrm{~cm}$ & & \\
\hline & & Airgap & $12 \mathrm{~cm}$ & & \\
\hline & & Madera Pino & $2,5 \mathrm{~cm}$ & Capa externa & \\
\hline & & \multicolumn{3}{|c|}{$\begin{array}{l}\text { Espacio de separación entre muro y elemento de protección } \\
\operatorname{solar}(15 \mathrm{~cm})\end{array}$} & \\
\hline & & Cerámica & $4 \mathrm{~cm}$ & Única capa & \\
\hline \multirow{6}{*}{65} & \multirow{6}{*}{ Guadua } & Madera Pino & $2,5 \mathrm{~cm}$ & Capa interna & \multirow{6}{*}{ On } \\
\hline & & Termoarcilla & $24 \mathrm{~cm}$ & & \\
\hline & & Airgap & $12 \mathrm{~cm}$ & & \\
\hline & & Madera Pino & $2,5 \mathrm{~cm}$ & Capa externa & \\
\hline & & \multicolumn{3}{|c|}{$\begin{array}{l}\text { Espacio de separación entre muro y elemento de protección } \\
\operatorname{solar}(15 \mathrm{~cm})\end{array}$} & \\
\hline & & Guadua & $2 \mathrm{~cm}$ & Única capa & \\
\hline \multirow{6}{*}{66} & & Madera Pino & $2,5 \mathrm{~cm}$ & Capa interna & \\
\hline & & Termoarcilla & $24 \mathrm{~cm}$ & & \\
\hline & & Airgap & $12 \mathrm{~cm}$ & & \\
\hline & Ladrillo Helios & Madera Pino & $2,5 \mathrm{~cm}$ & Capa externa & On \\
\hline & & Espacio de separac & $\begin{array}{l}\text { muro y } \\
\operatorname{ar}(15 \mathrm{~cm}\end{array}$ & to de protección & \\
\hline & & Cerámica Helios & $4 \mathrm{~cm}$ & Única capa & \\
\hline
\end{tabular}

A Tabla 5. Configuraciones de los modelos de simulación con muro doble con protección solar en los costados de mayor exposición oriente-occidente y zenit, con ventilación

Fuente: elaboración propia, 2013. 
temperatura interior del aire. Tales condiciones del prototipo son recreadas en el modelo para las simulaciones ambientales (Figura 2).

Para esta etapa del proyecto las mediciones y simulaciones se realizaron en el periodo entre octubre y diciembre de 2012, con recolección de datos a través de un data logger (registrador de datos) y un anemómetro, identificando el comportamiento de las 24 horas de un día, una vez por semana, a fin de poder contrastar los datos.

\section{Parámetros de diseño de tres casos propuestos}

Finalmente, con un modelo digital calibrado, y la experiencia de las mediciones y simulaciones realizadas, se propuso el diseño de tres sistemas de fachada diferenciados, para ser analizados mediante simulaciones ambientales. Estos sistemas fueron: Modelo 1 - Fachada doble capa (no ventilada) con masa térmica externa; Modelo 2 - Fachada en PVC sin masa térmica (ventilada); Modelo 3 - Fachada doble capa (no ventilada) con masa térmica interna (Figura 3).

Para ello se establecen tres fechas de análisis que contemplan las condiciones extremas a las cuales deberían responder los dos diseños, por lo cual las simulaciones se realizan el día de mayor temperatura identificado como el 5 de agosto; el día con la temperatura más baja, el 16 de noviembre, y el día de temperatura promedio registrado como el 28 de julio; tales simulaciones son elaboradas con intervalos horarios con el fin de establecer la incidencia de los elementos diseñados en términos de temperaturas en el transcurso de un día. Los archivos de datos climáticos son extraídos de la base de datos de Meteonorm (2018).

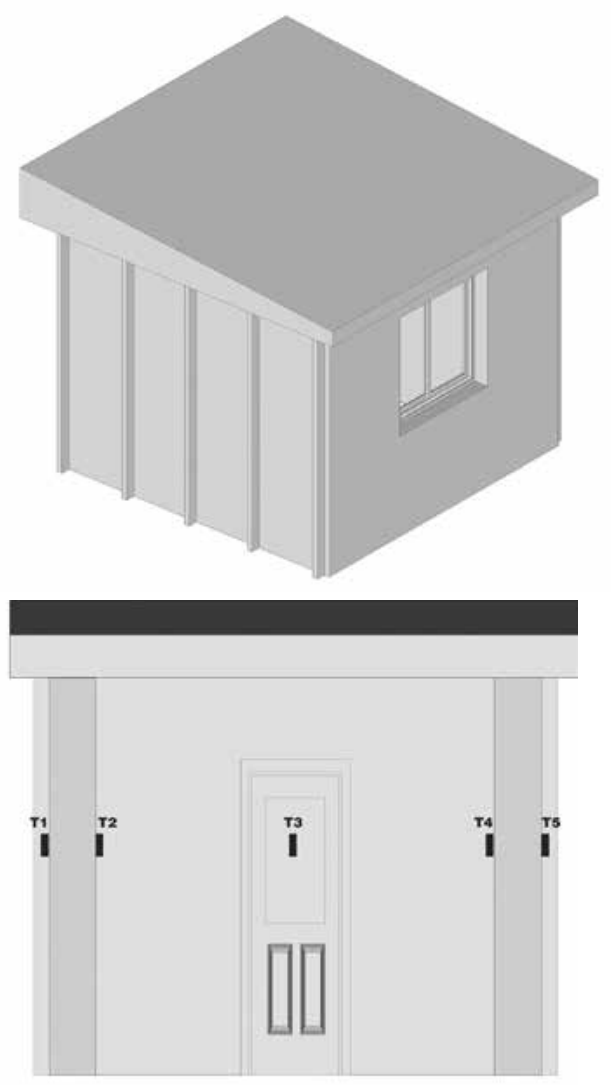

(A) Figura 2. Modelo básico y ubicación de termopares en el prototipo

Fuente: elaboración propia, 2017
En relación con la configuración del modelo de análisis, se establece como herramienta el software Design Builder ${ }^{\circledR}$ en funcionamiento con EnergyPlus ${ }^{\circledR}$, un software de código abierto desarrollado por el Departamento de Energía de Estados Unidos (U.S Departament of Energy / DOE, 2018). EnergyPlus es un motor de cálculo para simulaciones térmicas en edificaciones que permite modelar sistemas de ventilación natural usando un mecanismo de flujo de aire aproximado según Mateus, Pinto y Carrilho da Graça (2014, p. 515).

Según Blanco, Buruaga, Rojí, Cuadrado y Pelaz (2016, p. 327), Andelkovic, Mujan y Dakic (2016, p. 30) y Andarini (2014, p. 218), Design Builder ${ }^{\circledR}$ considera de manera precisa la incidencia de la radiación solar sobre los materiales, tanto como la radiación solar difusa y directa; además, permite de forma precisa, detallada y relativamente rápida, modelar geometrías en tres dimensiones de edificaciones para la evaluación de desempeño energético, confort térmico, ganancias o pérdidas de temperatura, producción de $\mathrm{CO}_{2}$ de sistemas activos, y análisis de fluido dinámico computacional, razón por la cual se escoge como herramienta de simulación en la investigación.

Teniendo en cuenta que, como mencionan Mateus et al. (2014, p. 515), las decisiones tomadas en el modelado de las zonas térmicas pueden tener impactos en los resultados, se diseñó el modelo como un edificio que contiene tres bloques: el primer edificio recoge los datos del modelo completo; el segundo, denominado "casa", resume los datos de la zona interior del prototipo, que permite verificar la temperatura del espacio revestido por los diseños que se van a analizar; el tercero, denominado "sistema", recoge los datos de análisis de la zona intermedia

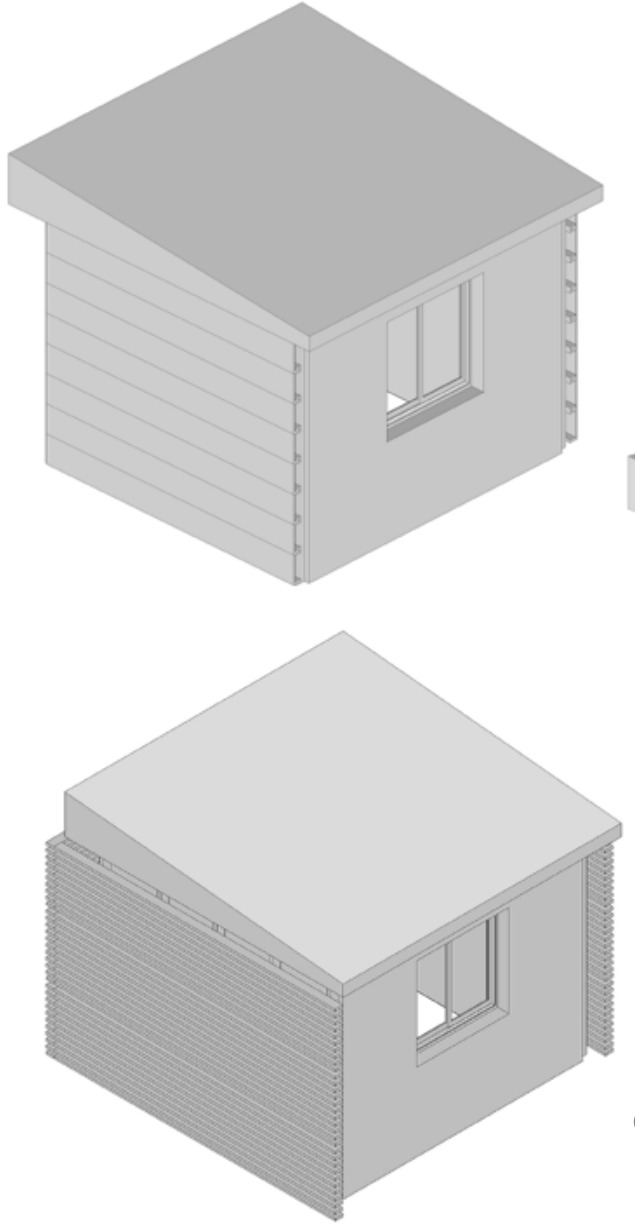

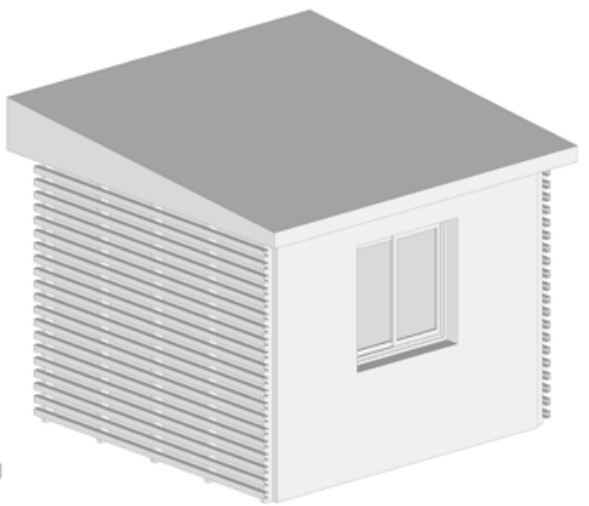

A Figura 3. Modelos con los dos diseños de revestimiento sobre modelo básico de PVC Fuente: elaboración propia, 2017. 
entre los diseños de fachada ventilada propuesta y el interior de la construcción.

La elaboración de las tres zonas establecidas permite recoger los resultados de temperatura asumiendo como parámetro de análisis la temperatura operativa que se presenta como promedio entre la temperatura del aire interior y la radiante; además de la temperatura de bulbo seco y la humedad relativa; asimismo, registrar resultados de superficie interior y exterior en relación con la temperatura de bulbo seco.

La descripción de las tres zonas coincide con el prototipo realizado, y es presentada en términos del edificio con actividad definida como desocupado, con muros externos en PVC de $2 \mathrm{~mm}$, con cámara de aire de $6 \mathrm{~cm}$ no ventilada y de nuevo recubrimiento de PVC de $2 \mathrm{~mm}$, cubierta de drywall de $12 \mathrm{~cm}$ no ventilada, y suelo de concreto de $12 \mathrm{~cm}$; ventanas con marco en madera de roble pintado en la fachada norte, y una puerta en madera y vidrio en la fachada sur. La zona denominada casa tiene las mismas condiciones; mientras que para la zona denominada sistema se considera la actividad para una zona estándar desocupada, con muros externos de PVC, en donde el muro oriental adyacente a la fachada ventilada diseñada, el suelo, las dos superficies laterales y la superficie superior se encuentran perforados por un vano. La cavidad de la fachada ventilada corresponde a $10 \mathrm{~cm}$, en concordancia con lo establecido por Poirazis (2004, p. 25), y Barbosa e Ip (2014, p. 1020), en donde el espesor de la cavidad varía de acuerdo con el diseño de la fachada y los requerimientos de mantenimiento y limpieza. En relación con la definición de los tres sistemas de fachada opaca diseñados en el modelo, se dispuso el sistema como bloques de componente (Tabla 6).

\section{Resultados}

\section{Simulaciones y estudios previos}

Los resultados de las 66 simulaciones realizadas demuestran que el Grupo 3 (modelos 28-45), modelos con cámara de aire, tienen el mejor comportamiento general, conservando temperaturas internas cercanas a las mínimas del día tal como se describe en Varini (2011, p. 5; 2013, p. 27) (Gráfica 1).

\section{Medición de prototipo en sitio para calibración de simulaciones}

Como resultado de las simulaciones para reconocer el desempeño del material PVC frente a materiales convencionales como la mampostería, se registró que el PVC redujo hasta $3{ }^{\circ} \mathrm{C}$ la temperatura, el 21 de julio que es un día de temperatura extrema, frente a la mampostería que redujo 2,2 oC centígrados de temperatura interior, es decir, el modelo compuesto por PVC presentó mejor desempeño. $\rightarrow$ Gráfica 1. Resultados de simulaciones realizadas comparando temperaturas máximas y mínimas exteriores e interiores

Fuente: elaboración propia, 2017.
Configuración de materiales en modelos de s imulación

\begin{tabular}{|c|c|c|c|c|c|}
\hline Modelo & Capa & Espesor (m) & $\begin{array}{l}\text { Conductividad } \\
\text { térmica }(W / m \\
K)\end{array}$ & $\begin{array}{l}\text { Densidad } \\
(\mathrm{kg} / \mathrm{m} 3)\end{array}$ & $\begin{array}{l}\text { Calor } \\
\text { específico } \\
(\mathrm{J} / \mathrm{kg} \mathrm{K})\end{array}$ \\
\hline \multirow{3}{*}{ Modelo básico } & PVC & 0,002 & 0,16 & 1380 & 1000 \\
\hline & Airgap & 0,06 & - & - & - \\
\hline & PVC & 0.002 & 0,16 & 1380 & 1000 \\
\hline \multirow{4}{*}{$\begin{array}{l}\text { Modelo } 1 . \text { Fachada doble } \\
\text { capa (no ventilada) con masa } \\
\text { térmica externa }\end{array}$} & PVC & 0,002 & 0,16 & 1380 & 1000 \\
\hline & Airgap & 0,06 & $\begin{array}{l}\cdots \cdots \\
-\end{array}$ & $\begin{array}{c}\cdots \cdots \\
-\end{array}$ & $\begin{array}{c}\cdots \cdots \\
-\end{array}$ \\
\hline & PVC & 0,002 & 0,16 & 1380 & 1000 \\
\hline & Concreto & 0,05 & 0,9 & 1950 & 840 \\
\hline \multirow{4}{*}{$\begin{array}{l}\text { Modelo 2. Fachada ventilada } \\
\text { en PVC (sin masa térmica) }\end{array}$} & PVC & 0,002 & 0,16 & 1380 & 1000 \\
\hline & Airgap & 0,06 & $\begin{array}{ll}- \\
\ldots \ldots\end{array}$ & $\begin{array}{c}- \\
\ldots \ldots\end{array}$ & - \\
\hline & PVC & 0,002 & 0,16 & 1380 & 1000 \\
\hline & Concreto & 0,05 & 0.9 & 1950 & 840 \\
\hline \multirow{4}{*}{$\begin{array}{l}\text { Modelo } 3 \text {. Fachada doble } \\
\text { capa (no ventilada) con masa } \\
\text { térmica interna }\end{array}$} & Revoque & 0,01 & 0,431 & 1250 & 1088 \\
\hline & Mampuesto & 0,11 & 0,711 & 2000 & $\begin{array}{l}3 \ldots \ldots \\
836.8\end{array}$ \\
\hline & Revoque & 0,01 & 0,431 & 1250 & 1088 \\
\hline & Concreto & 0,05 & 0,9 & 1950 & 840 \\
\hline
\end{tabular}

Comparación T Min T Max para cada sistema

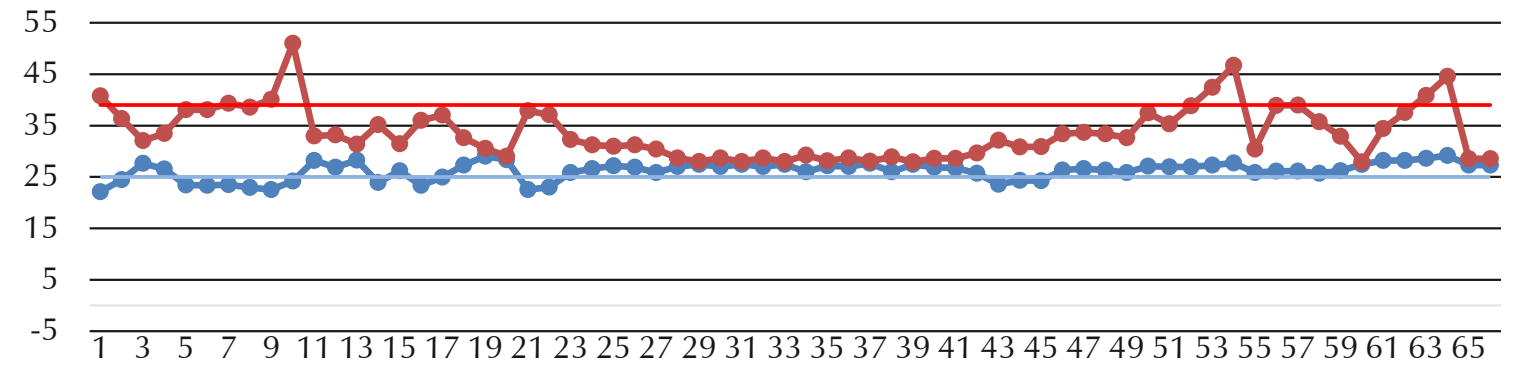

- Int Min C Int Max C Ext Min C Ext Max C 


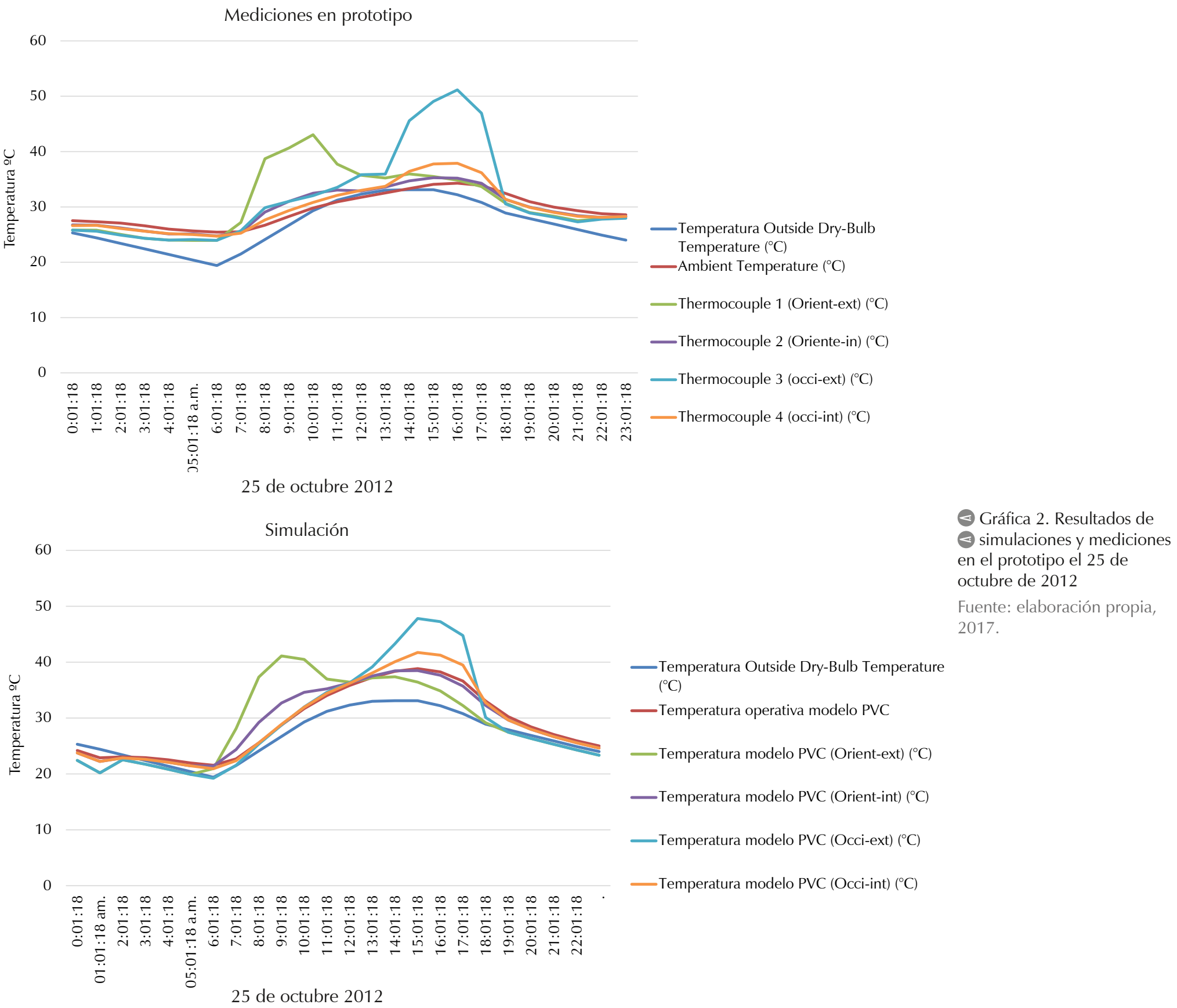

Respecto a las simulaciones del modelo en PVC frente a las mediciones del prototipo construido en Girardot, aunque estas develan tendencias similares en el comportamiento del material en el registro horario, como se presenta en el análisis del 25 de octubre (Gráfica 2), existen diferencias de temperatura al interior del espacio hasta de $6 \stackrel{\circ}{\circ}$ en casos como el 8 y 30 de noviembre, y 8 de diciembre.

Así, la confrontación de mediciones y simulaciones presentadas permitió identificar que aunque la construcción con PVC disminuye la temperatura al interior y permite una diferencia de esta entre la superficie interior y exterior que componen la edificación, el desempeño total no alcanza aún los valores de confort al interior del espacio; por tanto, es necesario hacer estudios sobre el diseño de revestimiento de fachada que complemente este sistema o contribuya a mejorar el desempeño térmico.

\section{Simulaciones finales para los tres casos propuestos}

Dado lo anterior, se realizaron simulaciones ambientales sobre el modelo en PVC presentado, para verificar el comportamiento de los dos diseños de revestimientos mencionados en las tres fechas seleccionadas (28 de julio, 5 de agosto y 16 de noviembre), diferenciando la temperatura exterior de bulbo seco y la temperatura operativa, y la divergencia entre los dos datos para dilucidar cuántos grados centígrados puede reducir o aumentar el sistema de fachada.

\section{Modelo 1}

En el análisis del modelo 1 en concreto se encontró que en la zona denominada edificio se registró una pérdida de calor hasta de $2,8{ }^{\circ} \mathrm{C}$ entre $1: 00$ y 2:00 a.m. el 28 de julio y 16 de noviembre $y$, de $1,2 \stackrel{\circ}{ } \mathrm{C}$ el 5 de agosto, y ganancia de calor hasta de 11,9 ${ }^{\circ} \mathrm{C}$ entre 2:00 y 3:00 p.m., consideradas las horas de mayor temperatura. En relación con la zona denominada casa, la pérdida de calor se redujo casi a la mitad el 16 de noviembre -hasta 1,5 $9 \mathrm{C}$ a la 1:00 a.m.-; el 28 de julio se redujo a $0,9 \stackrel{\circ}{\circ}$, y en agosto no hubo reducción, solo ganancia de calor hasta de $5,4 \stackrel{\circ}{ } \mathrm{C}$ entre 3:00 y 4:00 p.m., consideradas las horas de mayor temperatura (Gráfica 3).

\section{Modelo 2}

En el modelo 2, con el material de concreto, se encontró que en la zona denominada edificio 
จ Gráfica 3. Datos de simulación del modelo 1 en concreto, zona denominada casa

Fuente: elaboración propia, 2017.

$\rightarrow$ Gráfica 4. Datos de simulación del modelo 2 en concreto, zona denominada casa

Fuente: elaboración propia, 2017

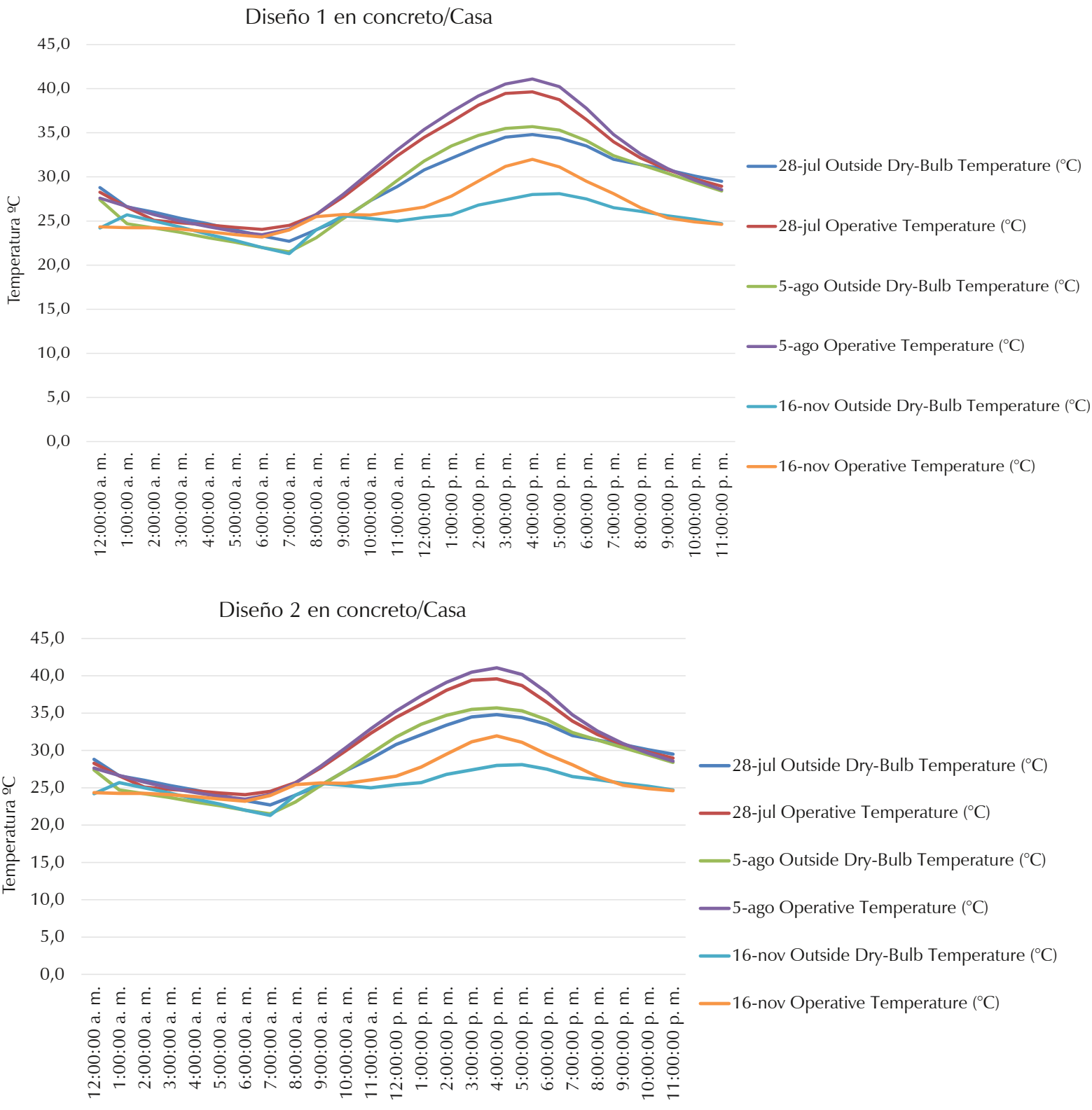

se registró una pérdida de calor hasta de $2,8 \stackrel{\circ}{\circ} \mathrm{C}$ entre 1:00 y 2:00 a.m. el 28 de julio y 16 de noviembre, y de 1,2 ${ }^{\circ} \mathrm{C}$ el 5 de agosto, y ganancia de calor hasta de 11,9 oC entre 2:00 y 3:00 p.m. consideradas las horas de mayor temperatura. En relación con la zona denominada casa, la pérdida de calor se redujo casi a la mitad el 16 de noviembre -hasta 1,4 ${ }^{\circ} \mathrm{C}$ a la 1:00 a.m.-; el 28 de julio se redujo a $0,9 \stackrel{\circ}{ }{ }^{\circ}$, y en agosto no hubo reducción, solo ganancia de calor hasta de 5,4 oC entre 3:00 y 4:00 p.m. (Gráfica 4).

\section{Modelo 3}

Con el análisis de las simulaciones es posible deducir que la incidencia de los dos sistemas anteriores sobre la temperatura interior de la zona denominada casa es muy baja, lo que puede atribuirse al espesor de los sistemas de fachada; por otra parte, aunque con una ligera diferencia, se deriva mejor desempeño en el modelo 2, que demuestra iguales pérdidas de calor pero menor ganancia de temperatura; no obstante, la temperatura interior sigue siendo muy alta, por lo que se hace necesario implementar además algunas estrategias pasivas, mencionadas en Velasco, Hudson y Luciani (2017, p. 999), como protección solar, masa térmica, ventilación nocturna, puestas a prueba con simulaciones sobre el modelo base en PVC.
Las nuevas estrategias comprenden, para la cubierta, una capa de aislamiento de $5 \mathrm{~cm}$ en poliestireno expandido sobre la configuración inicial, además de un elemento de sombreado a $50 \mathrm{~cm}$ de la cubierta, lo que crea una cámara de aire y protege de la radiación solar directa; con relación a la envolvente, se añadieron persianas como control solar a fin de reducir la absorción de calor por radiación directa; las persianas están dispuestas a $20 \mathrm{~cm}$ de la superficie externa del volumen y configuran una superficie ventilada; asimismo, se implementó la operación de aperturas para la ventilación natural nocturna sobre las ventanas, dispuestas en la parte superior de las superficies, a fin de permitir la ventilación cruzada, y se aumentó la masa térmica ampliando el espesor del muro a $50 \mathrm{~cm}$ en concreto (Gráfica 5).

La simulación del modelo con las estrategias de protección solar, aumento de masa térmica y ventilación nocturna, presenta una reducción de la temperatura interior de $8,6^{\circ} \mathrm{C}$ frente al modelo base sin fachada ventilada, y de 3,5 ${ }^{\circ} \mathrm{C}$ con respecto a la temperatura exterior, y evidencia mayor efectividad que los modelos anteriores en los que la reducción de temperatura frente al modelo base fue de aproximadamente $3,0^{\circ} \mathrm{C}$; también presenta disminución de temperaturas con respecto a la temperatura de bulbo seco (Gráfica 6). 

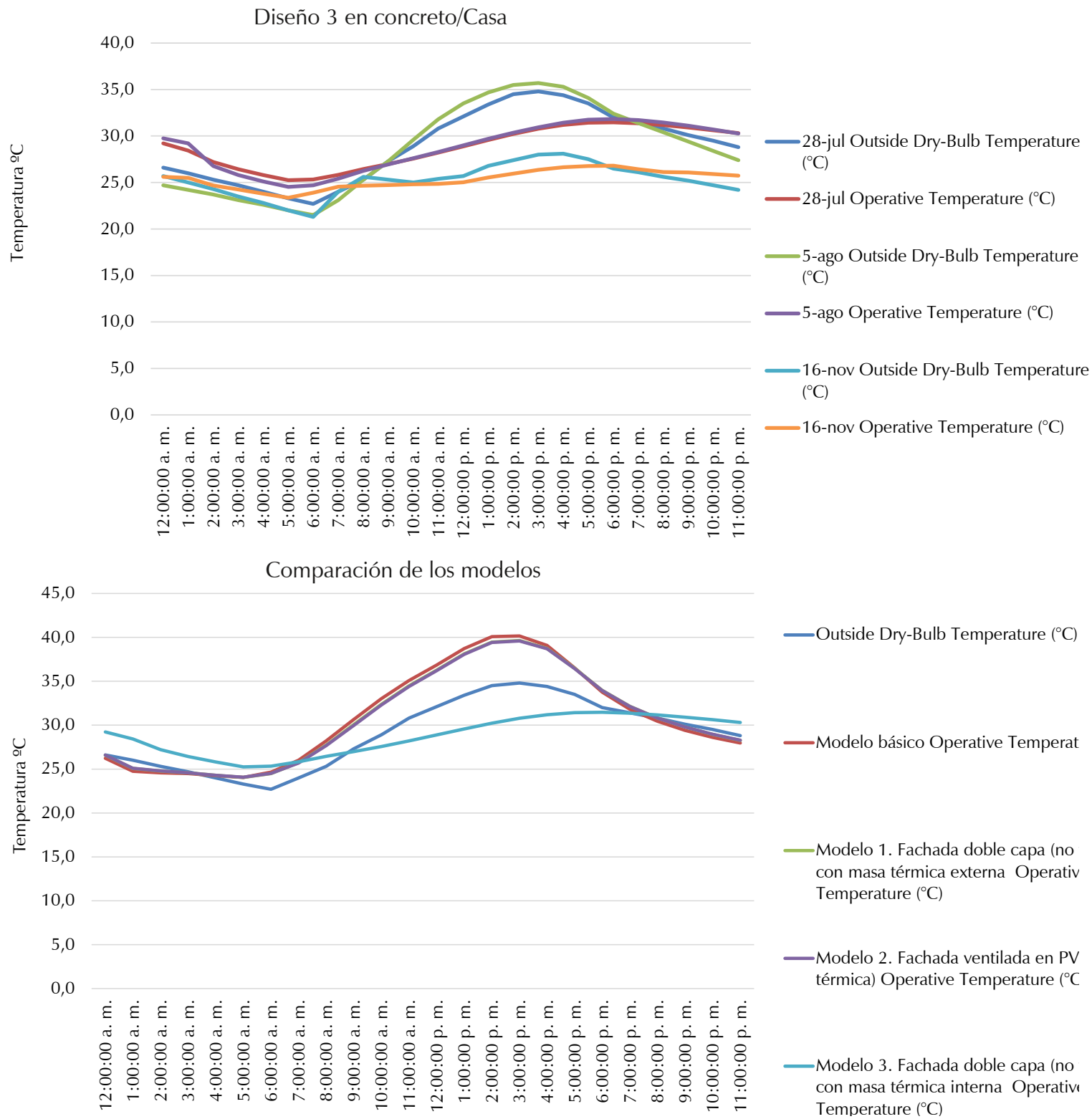

28 de julio

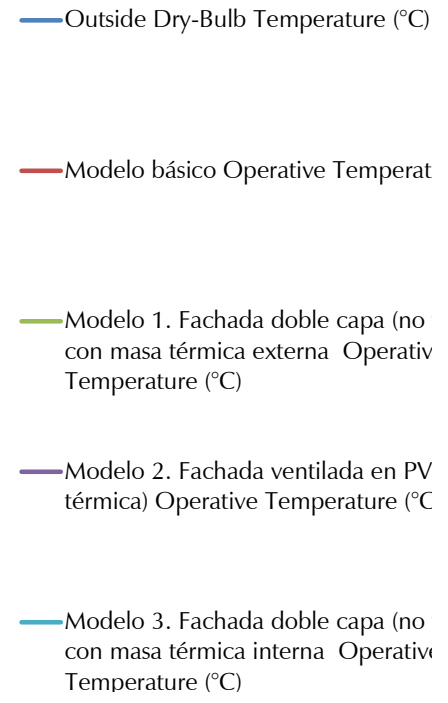
Temperature $\left({ }^{\circ} \mathrm{C}\right)$

\section{Discusión}

Con respecto a las diferencias encontradas entre las mediciones en sitio y las simulaciones, autores como Marinosci, Semprini y Morini (2014, p. 280) consideran que en general hay una dificultad por predecir el comportamiento de este tipo de sistemas, debido a la fuerte influencia de algunos parámetros como las cambiantes condiciones externas, tales como radiación solar y velocidad del viento; la configuración de patrones de flujos de aire y el comportamiento de la radiación de las superficies externas e internas.

Asimismo, Kim y Park (2011, p. 3636) sugieren que gran parte de las discrepancias entre simulaciones y mediciones pueden ser influenciadas por tres situaciones; la primera es la incertidumbre sobre los parámetros de entrada para las simulaciones y las mediciones; la segunda son las suposiciones o simplificaciones de la realidad durante el proceso de modelado; y por último, las limitaciones de la herramienta, que en el caso de Design Builder ${ }^{\circledR}$ en funcionamiento con EnergyPlus ${ }^{\circledR}$, las dificultades podrían presentarse en las opciones de simplificación del modelo, en las decisiones sobre el modelado de la totalidad del edificio o en la incertidumbre sobre los datos de entrada de los flujos de viento alrededor del edificio, esta última tam- bién mencionada por Kim y Park (2011, p. 3644) y Vernay, Raphael y Smith (2014, p. 412).

Otro aspecto por considerar sobre las diferencias entre simulaciones y mediciones es la fiabilidad de los archivos de datos climáticos con los que se realizan las simulaciones; según Pyrgou, Castaldo, Pisello, Cotana y Santamouris (2017, p. 224), los archivos comúnmente usados no consideran el impacto del fenómeno de microclima en contexto urbano ni lo eventos aleatorios de clima extremo, que pueden alterar significativamente el comportamiento térmico y energético de las edificaciones, lo que acarrea consecuencias no solo en las decisiones de los diseñadores e investigadores procurando predecir el desempeño térmico y energético, sino también para las industrias y los proyectos que buscan pronosticar la eficiencia de fuentes renovables de energía por medio de herramientas de simulación.

En el caso de Girardot, el archivo de datos climáticos extraído de la base de datos de Meteronorm está basado en información recogida por la estación meteorológica de Santiago, ubicada en el aeropuerto de Flandes, a una distancia de 6,14 km del sitio de construcción del prototipo que se encuentra en el área urbana, lo que explicaría por qué es más alta la temperatura en las mediciones en sitio que en las simulaciones; no obstante las
Gráfica 5. Datos de simulación del modelo 3, con estrategias en la zona denominada casa

Fuente: elaboración propia, 2017.
Gráfica 6. Datos de simulación de los modelos analizados

Fuente: elaboración propia, 2017. 
diferencias, hay que reconocer que las tendencias son similares y es posible comprender las dinámicas de funcionamiento de la edificación aun cuando los resultados numéricos no sean idénticos.

Por otra parte, sobre los resultados de los diseños de fachadas ventiladas con respecto al modelo base en PVC la discusión se centra en la relación costo-desempeño, al considerar que, aunque el sistema de fachada ventilada puede disminuir la temperatura interior en la edificación, la construcción de la misma aumentaría el valor de la inversión en construcción de la edificación; esto lleva a preguntarse si tal disminución de temperatura puede ser suficiente para no usar sistemas mecánicos de ventilación, y, de ser así, si es razonable el costo económico. En caso de no reducir suficientemente la temperatura al interior aumentaría el costo, no solo de construcción, sino además de consumo energético y disminución del área útil de la edificación, lo que incrementaría las desventajas de este sistema.

Asimismo, en cuanto al ahorro de consumo energético, Gratia y De Herde (2004, p. 1150) afirman que este puede ser reducido por el hecho de que la doble fachada puede disminuir el paso de luz al interior del espacio, lo que lleva a mantener encendido el sistema de iluminación por periodos prolongados, hecho que incrementa el costo total de consumo.

Por último, la simulación del modelo con las estrategias demuestra que hay mayor efectividad en aumentar la inercia térmica, y en ventilación nocturna; Gratia y De Herde (2007, p. 447) señalan que la ventilación natural nocturna reduce en general las cargas de refrigeración, y resaltan la importancia de la relación entre inercia térmica y disminución de la temperatura durante la noche; sumado a esto, Gagliano, Patania, Nocera y Signorello (2014, p. 369) afirman que el cierre de ventilación en horas diurnas es más efectivo, pero es contrario a las preferencias de los habitantes sobre la apertura de las ventanas durante el día.

El desarrollo de las simulaciones y mediciones de desempeño de las fachadas ventiladas en clima cálido húmedo permitió identificar que, como afirman Gaillard, Giroux-Julien, Ménézo y Pabiou (2014, p. 241), es indispensable monitorear los sistemas en prototipos a escala real como una herramienta para verificar y mejorar el comportamiento de los diseños de fachadas; así como el desarrollo de simulaciones térmicas como un medio para evaluar el desempeño energético; por esta razón, autores como Andarini (2014, p. 225) recomiendan el uso de las simulaciones durante la fase inicial de diseño debido a que en esta etapa hay más oportunidades de mejorar y realizar un diseño más cercano a la realidad. Esta herramienta permite también modelar diversos escenarios en función de obtener, no solo óptimos diseños, sino de optimizar la operación y el desempeño del mismo a fin de prever la respuesta de la edificación ante condiciones adversas.

Asimismo, este estudio permitió comprender la importancia de la creación de nuevos archivos climáticos que, como mencionan Pyrgou et al. (2017, p. 236), deben construirse a través de la recolección de estaciones climatológicas locales instaladas en áreas urbanas a fin de considerar fenómenos como los microclimas, o el efecto isla de calor, y las particularidades del clima en contexto urbano para reducir así el margen de error en las predicciones de comportamientos térmicos y energéticos, reforzando las decisiones de diseño en la búsqueda de resultados cercanos a la realidad.

En el contexto colombiano es necesaria la creación de archivos climáticos actualizados con las mediciones de los últimos años considerando las variaciones del clima propias del contexto urbano, pero en especial la creación de archivos de acceso abierto debido a que en la actualidad el único archivo de datos climáticos disponible abiertamente es el de la ciudad Bogotá, lo que dificulta la precisión de las simulaciones si se tiene en cuenta la diversidad geográfica del país y la particularidad de los climas locales.

\section{Conclusiones}

En términos generales, y de acuerdo con los resultados de las mediciones y simulaciones realizadas, es posible generar las siguientes conclusiones:

- Las fachadas de muro sencillo (sin cámara de aire) presentan desventajas en su desempeño comparadas con las que tienen cámara de aire, como se evidencia en las simulaciones iniciales; son mayores las diferencias de temperaturas máximas y mínimas de los modelos contenidos en el grupo 1.

- Las fachadas dobles y ventiladas requieren protección solar adicional en las superficies que reciben mayor radiación solar, en este caso oriental, occidental y cubierta; de otra manera su desempeño es bajo, como demuestra la diferencia entre los grupos 3 y 5 frente a los demás.

- El porcentaje de apertura exterior de las fachadas ventiladas debe ser controlado a fin de evitar superar el $5 \%$ del área total para impedir ganancias térmicas en horas de mayor temperatura externa, como lo demuestran las variaciones en grupos 4 y 5 .

- El grado de ventilación de la cavidad de aire no representa diferencias fundamentales en su desempeño; sin embargo, la ventilación restringida a horario nocturno presenta ventajas, como se evidencia en los resultados del grupo 5.

- La inercia térmica es un factor principal en el funcionamiento de las fachadas dobles, como se demuestra en los resultados iniciales de todos los grupos, y su posicionamiento al interior de la configuración hace una diferencia importante, como se demuestra comparando los resultados finales de los modelos 1, 2 y 3 .

De esa manera, se evidenció que si bien el uso de fachadas ventiladas puede resultar una estrategia viable para llegar a condiciones de confort en climas cálidos húmedos, esto sucede solamente cuando los diseños específicos integran el uso de estrategias pasivas, principalmente inercia térmica, protección solar y ventilación nocturna. Se encontró, sin embargo, que el uso de 
estas estrategias puede ser igualmente eficiente por sí solo, y requiere una menor inversión. Al mismo tiempo, las fachadas ventiladas pueden ser más complejas de controlar y modelar por las constantes variables del clima, tal como lo mencionan Gagliano et al. (2014, p. 362), sobre la ventilación natural. Por esta razón, como sugie ren Gratia y De Herde (2007, p. 447), es necesario el estudio de diversas configuraciones de fachadas ventiladas a fin de entender la complejidad y el comportamiento de los flujos de vientos que estos involucran en cada caso específico, ya que estas configuraciones ofrecen ventajas adicionales en términos de aislamiento acústico.

\section{Referencias}

Afonso, C. y Oliveira, A. (2000). Solar chimneys: simulation and experiment. Energy and Buildings (32), 71.79. Doi: https://doi.org/10.1016/ S0378-7788(99)00038-9

Andarini, R. (2014). The role of building thermal simulation for energy efficient building design. Energy Procedia (47), 217-226. Doi: https:// doi.org/10.1016/j.egypro.2014.01.217

Andelkovic, A. S., Mujan, I. y Dakic, S. (2016). Experimental validation of aEnergyPlus model: Application of a multi-storey naturally ventilated double skin façade. Energy and Buildings(118), 27-36. Doi: https://doi. org/10.1016/j.enbuild.2016.02.045

Aparicio-Fernández, C., Vivancos, J.-L., FerrerGisbert, P. y Royo-Pastor, R. (2014). Energy performance of a ventilated façade by simulation with experimental validation. Applied Thermal Engineering (66), 563-570. Doi: http://dx.doi.org/10.1016/j.applthermaleng.2014.02.041

Balocco, C. (2002). A simple model to study ventilated facades energy performance. Energy and Buildings (34), 469-475. Doi: https://doi. org/10.1016/S0378-7788(01)00130-X

Barbosa, S. e Ip, K. (2014). Perspectives of double skin façades for naturallyventilated buildings: A review. Renewable and Sustainable Energy Reviews (40), 1019-1029. Doi: https://doi. org/10.1016/j.rser.2014.07.192

Blanco, J. M., Buruaga, A., Rojí, E., Cuadrado, J. y Pelaz, B. (2016). Energy assessment and optimization of perforated metal sheet doubleskin façades through Design Builder. A case study in Spain. Energy and Buildings (111), 326-336. Doi: http://dx.doi.org/10.1016/j. enbuild.2015.11.053

Bolaños, T. y Moscoso, A. (2011). Consideraciones y selección de especies vegetales para su implementación en ecoenvolventes arquitectónicos: una herramienta metodológica. Revista Nodo, 5(10), 5-20. Recuperado de http://csifesvr.uan.edu.co/index.php/nodo/ article/view/138

Ciampi, M., Leccese, F. y Tuoni, G. (2003). Ventilated facades energy performance in summer cooling of buildings. Solar Energy (75), 491-502. Doi: https://doi.org/10.1016/j.solener.2003.09.010.

Design Builder (19 de octubre de 2017). Design Builder Software Ltd. Recuperado de https:// www.designbuilder.co.uk/

EnergyPlus (19 de octubre de 2017). EneryPlus. Recuperado de https://energyplus.net/

Fantucci, S., Marinosci, C., Serra, V. y Carbonaro, C. (2017). Thermal performance assessment of an opaque ventilated façade in the summer period: calibration of a simulation model through in-field measurements. Energy Procedia (111), 619-628. Doi: https://doi. org/10.1016/j.egypro.2017.03.224

Gagliano, A., Patania, F., Nocera, F. y Signorello, C. (2014). Assessment of the dynamic thermal performance of massive buildings. Energy and Buildings (72), 361-370. Doi: https://doi. org/10.1016/j.enbuild.2013.12.060

Gaillard, L., Giroux-Julien, S, Ménézo, C. y Pabiou, H. (2014). Experimental evaluation of a naturally ventilated PV double-skin building envelope in real operating conditions. Solar Energy (103), 223-241. Doi: http://dx.doi. org/10.1016/j.solener.2014.02.018
Ghaffarianhoseini, A., Ghaffarianhoseini, A. Berardi, U., Tookey, J., Hin Wa Li, D. y Kariminia, S. (2016). Exploring the advantages and challenges of double-skin façades (DSFs). Renewable and Sustainable Energy Reviews (60), 1052-1065. Doi: https://doi. org/10.1016/j.rser.2016.01.130

Giancola, E. Sanjuan, C., Blanco, E. y Heras, M R. (2012). Experimental assessment and modelling of the performance of an open joint ventilated façade during actual operating conditions in Mediterranean climate. Energy and Buildings (54), 363-375. Doi: http:// dx.doi.org/10.1016/j.enbuild.2012.07.035

Gratia, E. y De Herde, A. (2004). Optimal operation of a south double-skin facade. Energy and Buildings (36), 41-60. Doi: https://doi. org/10.1016/j.enbuild.2004.05.004

Gratia, E. y De Herde, A. (2007). Guidelines for improving natural daytime ventilation in an office building with a double-skin facade. Solar Energy (81), 435-448. Doi: https://doi. org/10.1016/j.solener.2006.08.006

Haase, M., Silva, F. M. y Amato, A. (2009). Simulation of ventilated facades in hot and humid climates. Energy and Buildings (41), 361-373. Doi: https://doi.org/10.1016/j. enbuild.2008.11.008

Høseggen, R., Wachenfeldt, B. J. y Hanssen, S. O. (2008). Building simulation as an assisting tool in decision making Case study: With or without a double-skin façade? Energy and Buildings (40), 821-827. Doi: https://doi. org/10.1016/j.enbuild.2007.05.015

Jentsch, M. F. Bahaj, A. S. y James, P. A. (2008). Climate change future proofing of buildings-Generation and assessment of building simulation weather files. Energy and Buildings, 40(12). 2148-2168. Doi: https://doi. org/10.1016/j.enbuild.2008.06.005

Kim, D.-W. y Park, C.-S. (2011). Difficulties and limitations in performance simulation of a double skin façade with EnergyPlus. Energy and Buildings (43), 3635-3645. Doi: https:// doi.org/10.1016/j.enbuild.2011.09.038

Marinosci, C., Semprini, G. y Morini, G. (2014). Experimental analysis of the summer thermal performances of a naturally ventilated rainscreen façade building. Energy and Buildings (72), 280-287. Doi: http://dx.doi. org/10.1016/j.enbuild.2013.12.044

Marinosci, C., Strachan, P., Semprini, G. y Morini, G. (2011). Empirical validation and modelling of a naturally ventilated rainscreen façade building. Energy and Buildings (43), 853-863. Doi: https://doi.org/10.1016/j. enbuild.2010.12.005

Mateus, N. M., Pinto, A. y Carrilho da Graça, G. (2014). Validation of EnergyPlus thermal simulation of a double skin naturallyand mechanically ventilated test cell. Energy and Buildings (75), 511-522. Doi: http://dx.doi. org/10.1016/j.enbuild.2014.02.043

Meteonorm (22 de 02 de 2018). Meteonorm. Recuperado de http://www.meteonorm.com/

Peci López, F., Jensen, R., Heiselberg, P. y Ruiz de Adana, M. (2012). Experimental analysis and model validation of an opaque ventilated facade. Building and Environment (56), 265275. Doi: https://doi.org/10.1016/j.buildenv.2012.03.017
Poirazis, H. (2004). Double Skin Façades for Office Buildings. Lund: Division of Energy and Building Design Department of Construction and Architecture Lund Institute of Technology Division of Energy and Building Design. Recuperado de http://www.ebd.Ith.se/fileadmin/energi byggnadsdesign/images/Publikationer/BokEBD-R3-G5 alt 2 Harris.pdf

Pyrgou, A., Castaldo, V. L., Pisello, A. L., Cotana, F. y Santamouris, M. (2017). Differentiating responses of weather files and local climate change to explain variations in building thermal-energy performance simulations. Solar Energy (153), 224-237. Doi: http://dx.doi. org/10.1016/j.solener.2017.05.040

Rubiano Martín, M. A. (2015). Ventajas del uso de fachada ventilada, en Giradot (Colombia). Revista Nodo, 10(19), 111-120. Recuperado de http://revistas.uan.edu.co/index.php/ nodo/article/view/538

Stec, W. J., Paassen, A. H. y Maziarz, A. (2005). Modelling the double skin façade with plants. Energy and Buildings (37), 419-427.Doi: https:// doi.org/10.1016/j.enbuild.2004.08.008

Theodosiou, T., Tsikaloudaki, K. y Bikas, D. (2017). Analysis of the thermal bridging effect on ventilated facades. Procedia Environmental Sciences (38), 397-404. Doi: https://doi. org/10.1016/j.proenv.2017.03.121

U.S. Department of Energy (22 de 02 de 2018). energy.gov. Recuperado de https://energy.gov/

Varini, C. (2011). Ecoenvolventes R \& D. Passive architectural envelopes high thermal performance and low environmental impact for tropical geo-climatic zones with cultivated native woods and plants. SB Helsinki World Sustainable Building Conference. Helsinki: Finnish Association of Civil Engineers RIL and VTT Technical Research Centre of Finland. Recuperdao de http://www.irbnet.de/daten/ iconda/CIB DC22949.pdf

Varini, C. (2013). Ecoenvelopes R\&D. Passive architectural envelopes high thermal performance and low environmental impact for tropical geoclimatic zones. Informes de la Construcción, 65, 23-30. Doi: https://doi. org/10.3989/ic.11.147

Velasco, R. y Robles, D. (2011). Eco-envolventes: A parametric design approach to generate and evaluate façade configurations for hot and humid climates. En T. Zupančič et al. (eds.), eCAADe 2011 Respecting fragile places: Proceedings of the 29th Conference on Education in Computer Aided Architectural Design in Europe (pp. 539-548). Ljubljana: Brussels: Education in Computer Aided Architectural Design in Europe; Ljubljana: Faculty of Architecture.

Velasco, R., Hudson, R. y Luciani, S. (2017). Tools and strategies to improve climate-driven façade design in the tropics: A pilot project for Colombia. 12th Conference on Advanced Building Skins (pp. 995-1003). Bern: Advanced Building Skins GmbH.

Vernay, D. G., Raphael, B. y Smith, I. F. (2014). Augmenting simulations of airflow around buildings using field measurements. Advanced Engineering Informatics (28), 412-424. Doi: http://dx.doi.org/10.1016/j.aei.2014.06.003 


\section{Enfoque y alcance}

La Revista de Arquitectura (Bogotá) (ISSN 1657-0308 Impresa y E-ISSN 2357-626X en línea) es una publicación seriada de acceso abierto, arbitrada mediante revisión por pares (doble ciego) e indexada, en donde se publican resultados de investigación originales e inéditos.

Está dirigida a la comunidad académica y profesional de las áreas afines a la disciplina. Es editada por la Facultad de Diseño y el Centro de Investigaciones (CIFAR) de la Universidad Católica de Colombia en Bogotá (Colombia).

La principal área científica a la que se adscribe la Revista de Arquitectura (Bogotá) según la OCDE es:

Gran área: 6. Humanidades

Área: 6.D. Arte

Disciplina: 6D07. Arquitectura y Urbanismo

También se publican artículos de las disciplinas como 2A02, Ingeniería arquitectónica; 5G03, Estudios urbanos (planificación y desarrollo); 6D07, Diseño.

Los objetivos de la Revista de Arquitectura (Bogotá) son:

- Promover la divulgación y difusión del conocimiento generado a nivel local, nacional e internacional

- Conformar un espacio para la construcción de comunidades académicas y la discusión en torno a las secciones definidas.

- Fomentar la diversidad institucional y geográfica de los autores que participan en la publicación.

- Potenciar la discusión de experiencias e intercambios científicos entre investigadores y profesionales.

- Contribuir a la visión integral de la arquitectura, por medio de la concurrencia y articulación de las secciones mediante la publicación de artículos de calidad.

- Publicar artículos originales e inéditos que han pasado por revisión de pares, para asegurar que se cumplen las normas éticas, de calidad, validez científica, editorial e investigativa.

- Fomentar la divulgación de las investigaciones y actividades desarrolladas en la Universidad Católica de Colombia.
Palabras clave de la Revista de Arquitectura (Bogotá): arquitectura, diseño, educación arquitectónica, proyecto y construcción, urbanismo.

Idiomas de publicación: español, inglés, portugués y francés.

Título abreviado: Rev. Arquit.

Titulo corto: RevArq

\section{Políticas de sección}

La revista se estructura en tres secciones correspondientes a las líneas de investigación activas y aprobadas por la institución, y dos complementarias, que presentan dinámicas propias de la Facultad de Diseño y las publicaciones relacionadas con la disciplina.

Cultura y espacio urbano. En esta sección se publican los artículos que se refieren a fenómenos sociales en relación con el espacio urbano, atendiendo aspectos de la historia, el patrimonio cultural y físico, y la estructura formal de las ciudades y el territorio.

Proyecto arquitectónico y urbano. En esta sección se presentan artículos sobre el concepto de proyecto, entendido como elemento que define y orienta las condiciones proyectuales que devienen en los hechos arquitectónicos o urbanos, y la forma como estos se convierten en un proceso de investigación y nuevo de conocimiento. También se presentan proyectos que sean resultados de investigación, los cuales se validan por medio de la ejecución y transformación en obra construida del proceso investigativo. También se contempla la publicación de investigaciones relacionadas con la pedagogía y didáctica de la arquitectura, el urbanismo y el diseño.

Tecnología, medioambiente y sostenibilidad. En esta sección se presentan artículos acerca de sistemas estructurales, materiales y procesos constructivos, medioambiente y gestión, relacionados con los entornos social-cultural, ecológico y económico.

Desde la Facultad. En esta sección se publican artículos generados en la Facultad de Diseño, relacionados con las actividades de docencia, extensión, formación en investigación o internacionalización, las cuales son reflejo de la dinámica y de las actividades realizadas por docentes, estudiantes y egresados; esta sección no puede superar el $20 \%$ del contenido.

Textos. En esta sección se publican reseñas, traducciones y memorias de eventos relacionados con las publicaciones en Arquitectura y Urbanismo.

\section{A Frecuencia de publicación}

Desde 1999 y hasta el 2015, la Revista de Arquitectura (Bogotá) publicó un volumen al año, a partir del 2016 se publicarán dos números por año en periodo anticipado, enero-junio y julio-diciembre, pero también maneja la publicación anticipada en línea de los artículos aceptados (versión Post-print del autor).

La Revista de Arquitectura (Bogotá) se divulga mediante versiones digitales (PDF, HTML, EPUB, XML) e impresas con un tiraje de 700 ejemplares, los tiempos de

Universidad Católica de Colombia (2018,
julio-diciembre).
Revista de Arquitectura (Bogotá),
20(2), I-I28. Doi: I0.I47/8
ISSN: 1657-0308
E-ISSN: 2357-626X
Especificaciones:
Formato: 34 x $24 \mathrm{~cm}$
Papel: Mate II5 g
Tintas: Negro y policromía

producción de estas versiones dependerán de los cronogramas establecidos por la editorial.

Los tiempos de recepción-revisión-aceptación pueden tardar entre seis y doce meses dependiendo del flujo editorial de cada sección y del proceso de revisión y edición adelantado.

Con el usuario y contraseña asignados, los autores pueden ingresar a la plataforma de gestión editorial y verificar el estado de revisión, edición o publicación del artículo.
A Canje

La Revista de Arquitectura está interesada en establecer canje con publicaciones académicas, profesionales o científicas del área de Arquitectura y Urbanismo, como medio de reconocimiento y discusión de la producción científica en el campo de acción de la publicación.

\section{Mecanismo}

Para establecer canje por favor descargar, diligenciar y enviar el formato: RevArq FP20 Canjes 
Universidad Católica de Colombia

Presidente

Édgar Gómez Betancourt

Vicepresidente - Rector

Francisco José Gómez Ortiz

Vicerrector Jurídico

Edwin de Jesús Horta Vásquez

Vicerrector Administrativo

Édgar Gómez Ortiz

Vicerrector Académico

Elvers Medellín Lozano

Director de Investigaciones

Edwin Daniel Durán Gaviria

Directora Editorial

Stella Valbuena García

\section{Facultad de Diseño}

Decano

Werner Gómez Benítez

Director de docencia

Jorge Gutiérrez Martínez

Directora de extensión

Adriana Pedraza Pacheco

Director de investigación

Hernando Verdugo Reyes

Director de gestión de calidad

Augusto Forero La Rotta

Comité asesor externo

Facultad de Diseño

Édgar Camacho Camacho

Martha Luz Salcedo Barrera

Samuel Ricardo Vélez
Facultad de Diseño

Centro de Investigaciones - CIFAR
Revista de acceso abierto

arbitrada e indexada

Publindex: Categoría B. Índice Bibliografico Nacional IBN.

Esci: Emerging Source Citation Index.

Doaj: Directory of Open Access Journals.

Redalyc: Red de Revistas Cientificas de América Latina y el Caribe, España y Portugal.

SciELO: Scientific Electronic Library Online - Colombia

Redib: Red Iberoamericana de Innovación y Conocimiento Cientifico.

Ebsco: EBSCOhost Research Databases.

Clase: Base de datos bibliográfica de revistas de ciencias sociales y

humanidades.

Latindex: Sistema Regional de Información en Línea para Revistas

Cientificas de América Latina, el Caribe, España y Portugal (Directorio

y catálogo).

Dialnet: Fundación Dialnet - Biblioteca de la Universidad de La Rioja.

LatinRev: Red Latinoamericana de Revistas Académicas en Ciencias

Sociales $y$ Humanidades.

Proquest: ProQuest Research Library.

Miar: Matrix for the Analysis of Journals.

Sapiens Research: Ranking de las mejores revistas colombianas según visibilidad internacional.

Actualidad Iberoamericana: (Índice de Revistas) Centro de Informació Tecnológica (CIT).

Google Scholar

Arla: Asociación de Revistas latinoamericanas de Arquitectura.

Editorial

Av. Caracas $N^{\circ} 46-72$, piso

Teléfono: 3277300 Ext. 5145

editorial@ucatolica.edu.co

www.ucatolica.edu.co

http://publicaciones.ucatolica.edu.co/

Impresión:

JAVEGRAF

Calle 46A No82-54 Int. 2

Bogotá, D. C., Colombia

http://www.javegraf.com.co/index.php

Agosto de 2018

\section{Revista de Arquitectura \\ (Bogotá)}

Director

Werner Gómez Benítez

Editor

César Eligio-Triana

Editores de sección

(1) Myriam Stella Díaz Osorio

(1) Carolina Rodríguez-Ahumada

(1) Anna Maria Cereghino Fedrigo

\section{Equipo editorial}

Coordinadora editorial

María Paula Godoy Casasbuenas mpgodoy@ucatolica.edu.co

Diseño y montaje

Juanita Isaza

juanaisaza@gmail.com

Traductoras

Inglés

Erika Tanacs

etanacs25@gmail.com

Portugués

Roanita Dalpiaz

roanitad@gmail.com

Correctora de estilo

María José Díaz Granados M.

mariajose_dgm@yahoo.com.co

Página Web

Centro de investigaciones (CIFAR)

Distribución y canjes

Claudia Álvarez Duquino

calvarez@ucatolica.edu.co
Comité editorial y científico

Cultura y espacio urbano

Carlos Mario Yory, PhD

Universidad Católica de Colombia. Bogotá, Colombia

Sonia Berjman, $\mathrm{PhD}$

ICOMOS-IFLA, Buenos Aires, Argentina

Juan Carlos Pérgolis, MSc Universidad Piloto de Colombia. Bogotá, Colombia

Beatriz García Moreno, PhD

Universidad Nacional de Colombia. Bogotá, Colombia

Proyecto arquitectónico y urbano

Jean-Philippe Garric, PhD, HDR

Université Paris I Panthéon-Sorbonne. Paris, Francia

Debora Domingo Calabuig, PhD

Universidad Politécnica de Valencia, España

Dania González Couret, PhD

Universidad Tecnológica de La Habana, Cuba

Hugo Mondragón López, PhD Pontificia Universidad Católica de Chile. Santiago, Chile

Juan Pablo Duque Cañas, PhD

Universidad Nacional de Colombia. Bogotá, Colombia

Tecnología, medioambiente y sostenibilidad

Mariano Vázquez Espí, PhD

Universidad Politécnica de Madrid, España

Denise Helena Silva Duarte, PhD Universidade de São Paulo (USP), Brasil

Luis Carlos Herrera Sosa, PhD Universidad Autónoma de Ciudad Juárez, México

Claudio Varini, PhD

Universidad Católica de Colombia. Bogotá, Colombia

Luis Gabriel Gómez Azpeitia, PhD Universidad de Colima. Colima, México 


\section{Contenido}

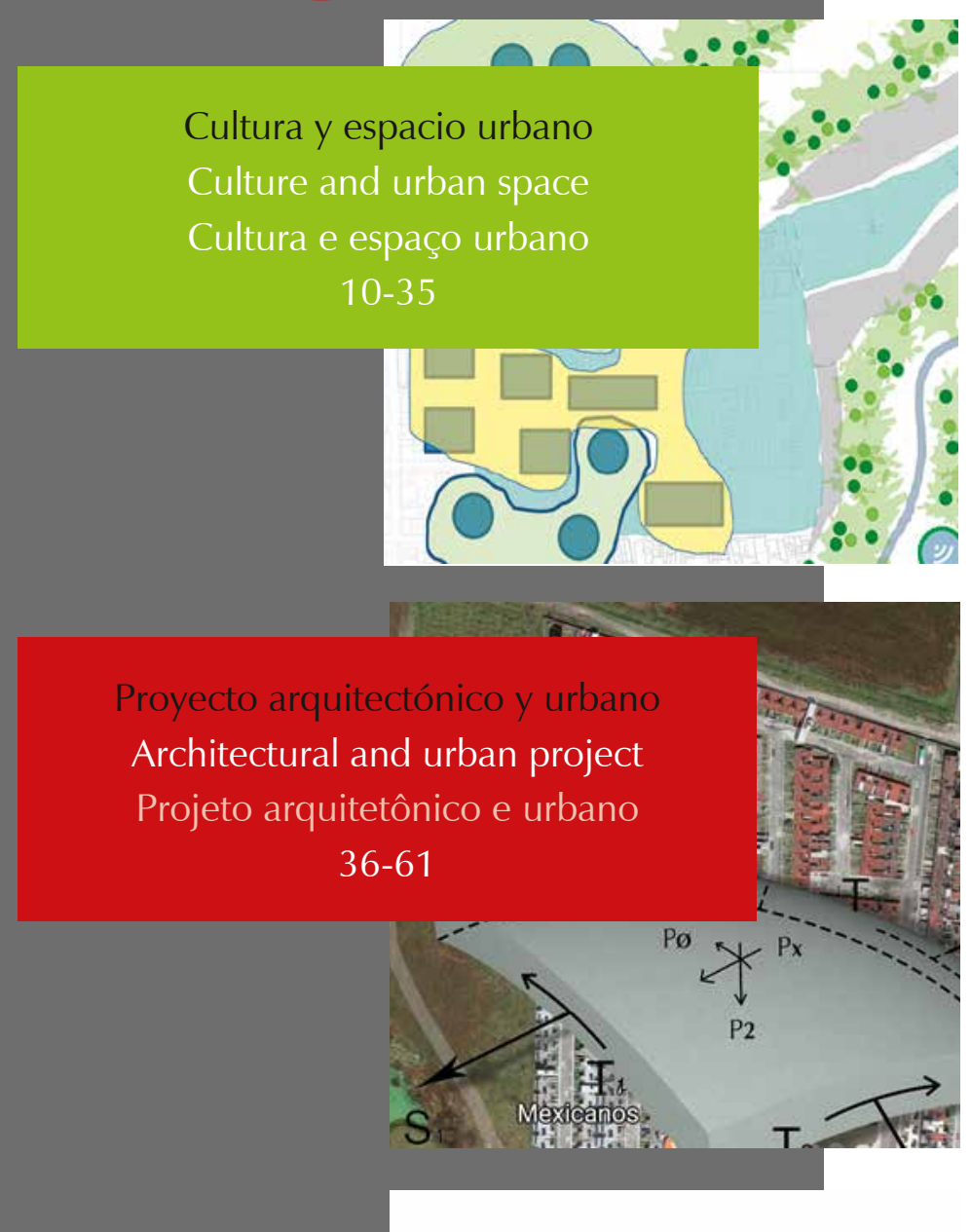

Tecnología, medioambiente

y sostenibilidad

Technology, environment and sustainability

Tecnologia, meio ambiente e sustentabilidade

62-89
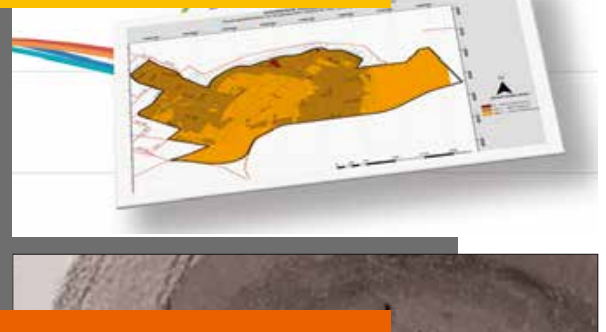

Desde la Facultad

From the Faculty

Da faculdade

90-109
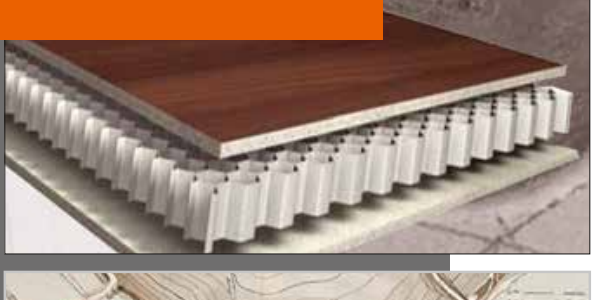

Textos

Texts

Textos

110-126

Los artículos científicos como herramienta de aprendizaje en las escuelas de arquitectura

Carolina Rodríguez-Ahumada

Pág. 3 ES

Paisaje urbano y espacio público como expresión de la vida cotidiana

Morella Briceño-Ávila

Pág. 10

\section{ES EN}

Habitar la quebrada: conformación de gradientes en las trazas vernaculares de los sectores altos de Valparaíso

\section{Omar Eduardo Cañete-Islas}

Juan Luis Moraga-Lacoste

Felipe Mateo López-Flores

Pág. 20

ES

Láminas cilíndricas en la arquitectura colombiana del siglo XX

Jorge Galindo-Díaz

Pág. 36

\section{ES EN}

Retórica simbólica en el espacio arquitectónico

Una mirada antropológica de la casa en la

sobremodernidad

Eska Elena Solano-Meneses

Pág. 51

ES

Ecoenvolventes: análisis del uso de fachadas ventiladas en clima cálido-húmedo

\footnotetext{
Sara Luciani-Mejía

Rodrigo Velasco-Gómez

Roland Hudson
}

Pág. 62

ES

Estrategias metodológicas de análisis urbano frente al cambio climático

Matriz para el diseño adaptativo en asentamientos informales

Adriana Patricia López-Valencia

Oswaldo López-Bernal

Pág. 78

ES

Muro panel térmico estructural compuesto

en guadua y cartón

Modelo experimental aplicado al clima de

la zona cafetera

Renato Cassandro-Cajiao

Pág. 90

\section{ES EN}

Continuidad y transformaciones de modelos

pedagógicos en la École Polytechnique (1867-1910)

Estelle Thibault

Traductores

Andrés Ávila-Gómez

Diana Carolina Ruiz

Pág. 110

ES 
La postulación de un artículo a la Revista de Arquitectura (Bogotá) indica que- el o los autores certifican que conocen y aceptan la política editorial, para lo cual firmarán en original y remitirán el formato RevArq FP00 Carta de originalidad.

La Revista de Arquitectura (Bogotá) maneja una política de Autoarchivo VERDE, según las directrices de SHERPA/RoMEO, por lo cual el autor puede:

- Pre-print del autor: Archivar la versión pre-print (la versión previa a la revisión por pares

- Post-print del autor: Archivar la versión post-print (la versión final posterior a la revisión por pares

- Versión de editor/PDF: Archivar la versión del editor - PDF/HTML/XLM en la maqueta de la Revista de Arquitectura (Bogotá).

El Autoarchivo se debe hacer respetando la licencia de acceso abierto, la integridad y la imagen de la Revista de Arquitectura (Bogotá), también se recomienda incluir la referencia, el vínculo electrónico y el DOI.

El autor o los autores son los titulares del Copyright (c) del texto publicado y la Editorial de la Revista de Arquitectura (Bogotá) solicita la firma de una autorización de reproducción del artículo (RevArq FP03 Autorización reproducción), la cual se acoge a la licencia CC, donde se expresa el derecho de primera publicación de la obra.

La Revista de Arquitectura (Bogotá) se guía por las normas internacionales sobre propiedad intelectual y derechos de autor, y de manera particular el artículo 58 de la Constitución Política de Colombia, la Ley 23 de 1982 y el Acuerdo 172 del 30 de septiembre de 2010 (Reglamento de propiedad intelectual de la Universidad Católica de Colombia)

Para efectos de autoría y coautoría de artículos se diferencian dos tipos: "obra en colaboración" y "obra colectiva". La primera es aquella cuya autoría corresponde a todos los participantes al ser fruto de su trabajo conjunto. En este caso, quien actúa como responsable y persona de contacto debe asegurar que quienes firman como autores han revisado y aprobado la versión final, y dan consentimiento para su divulgación. La obra colectiva es aquella en la que, aunque participan diversos colaboradores, hay un autor que toma la iniciativa la coordinación y realización de dicha obra. En estos casos, la autoría corresponderá a dicha persona (salvo pacto en contrario) y será suficiente únicamente con su autorización de divulgación.

El número de autores por artículo debe estar justificado por el tema, la complejidad y la extensión, y no deberá ser superior a la media de la disciplina, por lo cual se recomienda que no sea mayor de cinco. El orden en que se enuncien corresponderá a los aportes de cada uno a la construcción del texto, se debe evitar la autoría ficticia o regalada. Si se incluyen más personas que trabajaron en la investigación se sugiere que sea en calidad de colaboradores o como parte de los agradecimientos. La Revista de Arquitectura (Bogotá) respetará el número y el orden en que figuren en el original remitido. Si los autores consideran necesario, al final del artículo pueden incluir una breve descripción de los aportes individuales de cada uno de firmantes.

La comunicación se establece con uno de los autores, quien a su vez será el responsable de informar a los demás autores de las notificaciones emitidas por la Revista de Arquitectura (Bogotá).

En virtud de mantener el equilibro de las secciones y las mismas oportunidades para todos los participantes, un mismo autor puede postular dos o más artículos de manera simultánea; si la decisión editorial es favorable y los artículos son aceptados, su publicación se realizará en números diferentes.

\section{A Acceso abierto}

La Revista de Arquitectura (Bogotá), en su misión de divulgar la investigación y apoyar el conocimiento y la discusión en los campos de interés, proporciona acceso abierto, inmediato e irrestricto a su contenido de manera gratuita mediante la distribución de ejemplares impresos y digitales. Los interesados pueden leer, descargar, guardar, copiar y distribuir, imprimir, usar, buscar o referenciar el texto completo o parcial de los artículos o la totalidad de la Revista de Arquitectura (Bogotá).

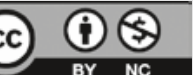

Esta revista se acoge a la licencia Creative Commons (CC BY NC de Atribución - No comercial 4.0 Internacional): "Esta licencia permite a otros entremezclar, ajustar y construir a partir de su obra con fines no comerciales, y aunque en sus nuevas creaciones deban reconocerle su autoría y no puedan ser utilizadas de manera comercial, no tienen que estar bajo una licencia con los mismos términos".

La Revista de Arquitectura es divulgada en centros y grupos de investigación, en bibliotecas y universidades, y en las principales facultades de Arquitectura mediante acceso abierto a la versión digital y suscripción anual al ejemplar impreso o por medio de canje, este último se formaliza mediante el formato RevArq FP20 Canjes

Para aumentar su visibilidad y el impacto de los artículos, se envían a bases de datos y sistemas de indexación y resumen (SIR) y, asimismo, pueden ser consultados y descargados en la página web de la revista.

La Revista de Arquitectura no maneja cobros, tarifas o tasas de publicación de artículo (Article Processing Charge-APC), o por el sometimiento de textos a la publicación.

\section{(1)Ética y buenas prácticas}

La Revista de Arquitectura se compromete a cumplir y respetar las normas éticas en todas las etapas del proceso de publicación. Los autores de los artículos publicados darán cumplimiento a los principios éticos contenidos en las diferentes declaraciones y legislaciones sobre propiedad intelectual y derechos de autor específicos del país donde se realizó la investigación. En consecuencia, los autores de los artículos postulados y aceptados para publicar, que presentan resultados de investigación, deben firmar la declaración de originalidad (formato RevArq FP00 Carta de originalidad).

La Revista de Arquitectura reconoce y adopta los principios de transparencia y buenas prácticas descritos por COPE, "Principles of Transparency and Best Practice in Scholarly Publishing" (2015).

El equipo editorial tiene la obligación de guardar la confidencialidad acerca de los artículos recibidos, y abstenerse de usar en sus propias investigaciones datos, argumentos o interpretaciones hasta tanto el artículo no sea publicado. También debe ser imparcial y gestionar los artículos de manera adecuada y en los plazos establecidos. La selección de revisores se hará con objetividad y estos deberán responder a la temática del artículo.

El editor, los autores y los revisores deben seguir las normas éticas internacionales definidas por el Committee on Publication Ethics (COPE), con el fin de evitar casos de:

- Fabricación, falsificación u omisión de datos.

- Plagio y autoplagio.

- Publicación redundante, duplicada o fragmentada.

- Omisión de referencias a las fuentes consultadas.

- Utilización de contenidos sin permiso o sin justificación.

- Apropiación individual de autoría colectiva.

- Cambios de autoría.

- Conflicto de interés (CDI) no revelado o declarado.

- Otras que pudieran surgir en el proceso de investigación y publicación. La fabricación de resultados se genera al mostrar datos inventados por los autores; la falsificación resulta cuando los datos son manipulados y cambiados a capricho de los autores; la omisión se origina cuando los autores ocultan deliberadamente un hecho o dato. El plagio se da cuando un autor presenta como ideas propias datos creados por otros. Los casos de plagio son los siguientes: copia directa de un texto sin entrecomillar o citar la fuente, modificación de algunas palabras del texto, paráfrasis y falta de agradecimientos; el autoplagio se da cuando el mismo autor reutiliza material propio que ya fue publicado, pero sin indicar la referencia al trabajo anterior. La revista se apoya en herramientas digitales que detectan cualquiera de estos casos en los artículos postulados, y es labor de los editores y revisores velar por la originalidad y fidelidad en la citación. La publicación redundante o duplicada se refiere a la copia total, parcial o alterada de un trabajo ya publicado por el mismo autor

En caso de sospechar de alguna mala conducta se recomienda seguir los diagramas de flujo elaborados por COPE (2008), con el fin de determinar las acciones correspondientes.

La Revista de Arquitectura se reserva el derecho de retractación de publicación de aquellos artículos que, posterior a su publicación, se demuestre que presentan errores de buena fe, o cometieron fraudes o malas prácticas científicas. Esta decisión se apoyará en "Retraction Guidelines" (COPE, 2009). Si el error es menor, este se podrá rectificar mediante una nota editorial de corrección o una fe de erratas. Los autores también tienen la posibilidad de solicitar la retractación de publicación cuando descubran que su trabajo presenta errores graves. En todos los casos se conservará la versión electrónica y se harán las advertencias de forma clara e inequívoca.

\section{A Privacidad y manejo de la información.} Habeas Data

Para dar cumplimiento a lo previsto en el artículo 10 del Decreto 1377 de 2013, reglamentario de la Ley 1581 de 2012, y según el Acuerdo 002 del 4 de septiembre de 2013 de la Universidad Católica de Colombia, "por el cual se aprueba el manual de políticas de tratamiento de datos personales":

La Universidad Católica de Colombia, considerada como responsable o encargada del tratamiento de datos personales, manifiesta que los datos personales de los autores, integrantes de los comités y pares revisores, se encuentran incluidos en nuestras bases de datos; por lo anterior, y en cumplimiento de las disposiciones legales vigentes, la Universidad solicitará siempre su autorización, para que en desarrollo de sus funciones propias como Institución de Educación Superior, en especial las relacionadas con la docencia, la extensión y la investigación, la Universidad Católica de Colombia pueda recolectar, recaudar, almacenar, usar, circular, suprimir, procesar, intercambiar, compilar, dar tratamiento, actualizar, transmitir o transferir a terceros países y disponer de los datos que le han suministrado y que han sido incorporados en las bases de datos de todo tipo que reposan en la Universidad.

La Universidad Católica de Colombia queda autorizada, de manera expresa e inequívoca, en los términos señalados por el Decreto 1377 de 2013, para mantener y manejar la información de nuestros colaboradores (autores, integrantes de los diferentes comités y pares revisores); así mismo, los colaboradores podrán ejercer sus derechos a conocer, actualizar, rectificar y suprimir sus datos personales, para lo cual se han dispuesto las siguientes cuentas de correo electrónico: 
La Revista de Arquitectura (Bogotá) recibe artículos de manera permanente. Los artículos se procesan a medida que se postulan, dependiendo el flujo editorial de cada sección.

El idioma principal es el español, y como opcionales están definidos el inglés, el portugués y el francés; los textos pueden ser escritos y presentados en cualquiera de estos.

Los artículos postulados deben corresponder a las categorías universalmente aceptadas como producto de investigación, ser originales e inéditos y sus contenidos responder a criterios de precisión, claridad y brevedad.

Como punto de referencia se pueden tomar las tipologías y definiciones del Índice Bibliográfico Nacional, Publindex (2010) que se describen la continuación:

1. Artículo de revisión: documento resultado de una investigación terminada donde se analizan, sistematizan e integran los resultados de investigaciones publicadas o no publicadas, sobre un campo en ciencia o tecnología, con el fin de dar cuenta de los avances y las tendencias de desarrollo. Se caracteriza por presentar una cuidadosa revisión bibliográfica de por lo menos 50 referencias.
2. Artículo de investigación científica y tecnológica: documento que presenta, de manera detallada, los resultados originales de proyectos terminados de investigación. La estructura generalmente utilizada contiene cuatro apartes importantes: introducción, metodología, resultados y conclusiones.

3. Artículo de reflexión: documento que presenta resultados de investigación terminada desde una perspectiva analítica, interpretativa o crítica del autor, sobre un tema específico, recurriendo a fuentes originales.

Adicional a estas tipologías, se pueden presentar otro tipo de artículos asociados a procesos de investigación-creación y/o investigación proyectual. En todos los casos se debe presentar la información suficiente para que cualquier investigador pueda reproducir la investigación y confirmar o refutar las interpretaciones defendidas y sea evidente el aporte a la disciplina.

En todos los casos se debe presentar la información suficiente para que cualquier investigador pueda reproducir la investigación y confirmar o refutar las interpretaciones defendidas.

\section{(A) Instrucciones para postular artículos}

Postular el artículo en la página web de la Revista de Arquitectura (Bogotá) y adjuntar comunicación escrita dirigida al editor RevArq_FP00 Carta de originalidad (debidamente firmada por todos los autores en original); de igual manera, se debe diligenciar el formato de hoja de vida RevArq FP01 Hoja de Vida (una por cada autor).

En la comunicación escrita el autor expresa que conoce y acepta la política editorial de la Revista de Arquitectura (Bogotá), que el artículo no está postulado para publicación simultáneamente en otras revistas u órganos editoriales y que no existe conflicto de intereses (ver modelo RevArq FP06 CDI) y que, de ser aceptado, concederá permiso de primera publicación, no exclusiva a nombre de la Universidad Católica de Colombia como editora de la revista.

Los artículos deben tener en cuenta las siguientes recomendaciones:

- En la primera página del documento se debe incluir:

Tírulo: no exceder 15 palabras

Subtítulo: opcional, complementa el título o indica las principales subdivisiones del texto.

Nombre del autor o autores: nombres y apellidos completos o según modelo de citación adoptado por el autor para la normalización de los nombres del investigador. Como nota al pie (máximo 150 palabras): formación académica, experiencia profesional e investigativa, vinculación laboral, código https://orcid.org/, premios o reconocimientos, publicaciones representativas e información de contacto, correo electrónico.

Filiación institucional: debajo del nombre se debe declarar la ins-titución en la cual se desarrolló el producto, de la cual recibió apoyo o aquella que respalda el trabajo investigativo.

Resumen: debe ser analítico, se redacta en un solo párrafo, da cuenta del tema, el objetivo, la metodología, los resultados y las conclusiones; no debe exceder las 150 palabras.

Palabras clave: cinco palabras o grupo de palabras, ordenadas alfabéticamente y que no se encuentren en el título o subtítulo; estas sirven para clasificar temáticamente al artículo. Se recomienda emplear principalmente palabras definidas en el tesauro de la Unesco (http://databases. unesco.org/thessp/), en el tesauro de Arte \& Arquitectura (C) (www.aatespanol.cl), o Vitruvio (http://vocabularyserver.com/vitruvio/)

También se recomienda incluir título, resumen y palabras clave en segundo idioma.

- La segunda página y siguientes deben tener en cuenta:

El cuerpo del artículo se divide en: Introducción, Metodología, Resultados y Discusión de resultados; posteriormente se presentan las Conclusiones, y luego las Referencias bibliográficas y los Anexos (método IMRYD). Las tablas y figuras se deben incorporar en el texto.

Descripción del proyecto de investigación: en la introducción se debe describir el tipo de artículo y brevemente el marco investigativo del cual es resultado y diligenciar el formato (RevArq FP02 Info Proyectos de Investigación).

TEXTO: todas las páginas deben venir numeradas y con el título de artículo en la parte superior de la página. Márgenes de $3 \mathrm{~cm}$ por todos los lados, interlineado doble, fuente Arial o Times New Roman de 12 puntos, texto justificado (Ver plantilla para presentación de artículos). La extensión de los artículos debe ser de alrededor de 5.000 palabras ( \pm 20 páginas, incluyendo gráficos, tablas, referencias, etc.); como mínimo 3.500 y máximo 8.000 palabras. Se debe seguir el estilo vigente y recomendado en el Manual para Publicación de la American Psychological Association (APA). (Para mayor información véase http://www.apastyle.org/)
Citas y notas al pie: las notas aclaratorias o notas al pie no deben exceder cinco líneas o 40 palabras, de lo contrario estas deben ser incorporadas al texto general. Las citas pueden ser:

Corta: (con menos de 40 palabras) se incorporan al texto y pueden ser: textuales (se encierran entre dobles comillas), parafraseo o resumen (se escriben en palabras del autor dentro del texto).

Cita textual extensa: (mayor de 40 palabras) debe ser dispuesta en un renglón y un bloque independiente con sangrías y omitiendo las comillas, no olvidar en ningún caso la referencia del autor (Apellido, año, página).

Referencias: como modelo para la construcción de referencias se emplea el estilo recomendado en el Manual para Publicación de la American Psychological Association (APA) (http://www.apastyle.org/).

Siglas: en caso de emplear siglas en el texto, las figuras o las tablas, se debe proporcionar la equivalencia completa la primera vez que se empleen y encerrarlas entre paréntesis. En el caso de citar personajes reconocidos se deben colocar nombres o apellidos completos, nunca emplear abreviaturas.

Figuras y tablas: las figuras (gráficos, diagramas, ilustraciones, planos, mapas o fotografías) y las tablas deben ir numeradas y contener título o leyenda explicativa relacionada con el tema del artículo, que no exceda las 15 palabras (Figura 1. xxxxx, Tabla 1. xxxx, etc.) y la procedencia (fuente: autor o fuente, año, página). Estas se deben referenciar en el texto de forma directa o entre paréntesis; se recomienda hacerlo con referencias cruzadas.

También se deben entregar en medio digital, independiente del texto, en formatos editables o abiertos. La marcación de los archivos debe corresponder a la incluida en el texto. Según la extensión del artículo se deben incluir de 5 a 10 gráficos. Ver guía para la búsqueda de imágenes de dominio público o bajo licencias Creative Commons (CC).

El autor es el responsable de adquirir los derechos o las autorizaciones de reproducción a que haya lugar para imágenes o gráficos tomados de otras fuentes, así como de entrevistas o material generado po colaboradores diferentes a los autores; de igual manera, se debe garantizar la protección de datos e identidades para los casos que sea necesario.

Fotografía: pueden ser entregadas en original para ser digitalizadas, de lo contrario se deben digitalizar con una resolución igual o superior a 300 dpi para imágenes a color y 600 para escala de grises. Los formatos de las imágenes pueden ser TIFF, PSD o JPG, y deben cumplir con las características expresadas en el punto anterior (figuras).

Planimetría: se debe entregar la planimetría original en medio digital, en lo posible en formato CAD, y sus respectivos archivos de plumas o en PDF; de no ser posible, se deben hacer impresiones en tamaño carta con las referencias de los espacios mediante numeración y lista adjunta. Deben tener escala gráfica, escala numérica, norte, coordenadas y localización. En lo posible, no deben contener textos, achurados o tramas.

Para más detalles, consultar el documento RevArq Parámetros para Autores Descripción en el portal web de la Revista de Arquitectura (Bogotá)

\section{Beneficios}

Como reconocimiento a los autores, se les hará envío postal de dos ejemplares de la edición impresa sin ningún costo y entregada en la dirección consignada en el formato de hoja de vida (RevArq FP01); adicionalmente, se enviará el vínculo para la descarga de la versión digital.

También se enviará una constancia informativa en la que se relaciona a publicación del artículo y, de manera opcional, se pueden detallar las fechas del proceso editorial y el arbitraje realizado. 
La selección de revisores se realiza de acuerdo con los siguientes criterios:

- Afinidad temática.

- Formación académica.

- Experiencia investigativa y profesional.

- Producción editorial en revistas similares o en libros resultado de investigación.

El proceso de arbitraje se basa en los principios de equidad e imparcialidad, y en los criterios de calidad y pertinencia.

El desarrollo de la revisión se realiza según el formato (RevArq FP10 Evaluación de artículos) y las observaciones que el revisor considere necesarias en el cuerpo del artículo. En cualquiera de los conceptos que emita el revisor (Aceptar, Publicable con modificaciones, Reevaluable o No publicable), y como parte de la labor formativa y de comunidad académica, el revisor hará sugerencias para mejorar el documento. El revisor podrá solicitar una nueva relectura del artículo después de los ajustes realizados por el autor.

El revisor también deberá diligenciar el formato RevArq FP01 Hoja de Vida, con el fin de certificar y soportar el proceso de revisión ante los SIR que así lo soliciten.

En el proceso de arbitraje se emplea el método doble ciego, los nombres del revisor no serán conocidos por el autor y viceversa. Con el fin de garantizar el anonimato del autor, al artículo postulado se le han podido suprimir nombres, instituciones o imágenes que puedan ser asociadas de manera directa al autor.

Aunque se procura el anonimato, una vez recibida la invitación como par revisor del artículo, el revisor debe cerciorarse de que no exista conflicto de intereses (CDI) o alguna limitante que afecte la revisión o que pueda ser vista como tal (lazos familiares, amistad o enemistad, vínculos contractuales o laborales, posiciones éticas, etc.), de presentarse esta situación se notificara al editor. (Ver modelo RevArq FP06 CDI).

Dada la confidencialidad del proceso de revisión, y considerando los derechos de autor y de propiedad intelectual que pueda haber sobre el material que se entrega, el revisor se compromete a mantener en absoluta reserva su labor, a limitar el uso de la obra entregada solo para el propósito designado y a devolver la documentación remitida una vez concluya la actividad.

El tiempo establecido para las revisiones de pares es de máximo un mes a partir de la confirmación de la recepción de la documentación. Ese plazo podrá ser modificado de mutuo acuerdo entre el editor y el revisor, siempre y cuando no afecte la periodicidad de la revista, la impresión o el tiempo para emitir una respuesta al autor.

Los revisores se acogerán a "COPE Ethical Guidelines for Peer Reviewers" de COPE.

\section{Beneficios}

Como retribución a los revisores se les hará envío postal de un ejemplar de la edición impresa sin ningún costo y entregada en la dirección consignada en el formato de hoja de vida. También, si es de interés para el revisor, podrá hacer la solicitud de alguna de las publicaciones editadas y presentes en el catálogo de publicaciones de la UNIVERSIDAD CATÓLICA DE COLOMBIA, previa aprobación de la Editorial y sujeto a la disponibilidad.

Si lo desea tendrá derecho a una constancia de la colaboración en la revisión de artículos, la cual solo contendrá el periodo en el cua se realizó la actividad. También tendrá la posibilidad de aceptar o no la publicación de su nombre, nacionalidad y nivel máximo de formación en la página web de la Revista de Arquitectura (Bogotá) en su calidad de colaborador.

\section{A Proceso de revisión por pares}

Luego de la postulación del artículo, el editor de la Revista de Arquitectura (Bogotá) selecciona y clasifica los artículos que cumplen con los requisitos establecidos en las directrices para los autores. El editor podrá rechazar en primera instancia artículos, sin recurrir a un proceso de revisión, si los considera de baja calidad o por presentar evidencias de faltas éticas o documentación incompleta.

Los artículos se someterán a un primer dictamen del editor, de los editores de sección y del Comité Editorial, teniendo en cuenta:

- Afinidad temática, relevancia del tema y correspondencia con las secciones definidas.

- Respaldo investigativo.

- Coherencia en el desarrollo del artículo, así como una correcta redacción y ortografía.
- Relación entre las figuras y tablas con el texto del artículo.

En esta revisión se verificará el nivel de originalidad mediante el uso de software especializado (Ithenticate o similar) y recursos digitales existentes para tal fin, también se observará la coherencia y claridad en los apartados del documento (modelo IMRYD) la calidad de las fuentes y la adecuada citación, esto quedará consignado en el formato (RevArq FP09 Revisión de artículos); esta información será cargada a la plataforma de gestión editorial y estará a disposición del autor.

En caso de que el artículo requiera ajustes preliminares, será devuelto al autor antes de ser remitido a revisores. En este caso, el autor tendrá veinte días para remitir nuevamente el texto con los ajustes solicitados.

Después de la preselección se asignan mínimo dos revisores especializados, quienes emitirán su concepto utilizando el formato (RevArq FP10 Evaluación de artículos) y las anotaciones que consideren oportunas en el texto; en esta etapa se garantizará la confidencialidad y el anonimato de autores y revisores (modalidad doble ciego)

Del proceso de revisión se emite uno de los siguientes conceptos que será reportado al autor:

- Aceptar el envío: con o sin observaciones.

- Publicable con modificaciones: se podrá sugerir la forma más adecuada para una nueva presentación, el autor puede o no aceptar las observaciones según sus argumentos. Si las acepta, cuenta con quince días para realizar los ajustes pertinentes.

- Reevaluable: cumple con algunos criterios y debe ser corregido. Es necesario hacer modificaciones puntuales y estructurales al artículo. En este caso, el revisor puede aceptar o rechazar hacer una nueva lectura del artículo luego de ajustado.

- No publicable: el autor puede volver a postular el artículo e iniciar nuevamente el proceso de arbitraje, siempre y cuando se evidencien los ajustes correspondientes.

En el caso de presentarse diferencias sustanciales y contradictorias en los conceptos sobre la recomendación del revisor, el editor remitirá el artículo a un revisor más o a un miembro del Comité Editorial quien podrá actuar como tercer árbitro, con el fin de tomar una decisión editorial sobre la publicación de artículo.

Los autores deberán considerar las observaciones de los revisores o de los editores, y cada corrección incorporada u omitida debe quedar justificada en el texto o en una comunicación adjunta. En el caso que los autores omitan las indicaciones realizadas sin una argumentación adecuada, el artículo será devuelto y no se dará por recibido hasta que no exista claridad al respecto. El editor respetará la independencia intelectual de los autores y a estos se les brindará el derecho de réplica en caso de que los artículos hayan sido evaluados negativamente y rechazados. Los autores, con su usuario y contraseña, podrán ingresar a la plataforma de Gestión Editorial, donde encontrarán los conceptos emitidos y la decisición sobre el artículo.

El editor y el Comité Editorial se reservan el derecho de aceptar o no la publicación del material recibido. También se reservan el derecho de sugerir modificaciones de forma, ajustar las palabras clave o el resumen y de realizar la corrección de estilo. El autor conocerá la versión final del texto antes de la publicación oficial del mismo.

Cuando un artículo es aceptado para su publicación, el autor debe firmar la autorización de reproducción (RevArq FP03 Autorización reproducción). Para más información ver: Política de derechos de autor

\section{Notas aclaratorias:}

La Revista de Arquitectura (Bogotá) busca el equilibrio entre las secciones, motivo por el cual, aunque un artículo sea aceptado o continúe en proceso de revisión, podrá quedar aplazado para ser publicado en un próximo número; en este caso, el autor estará en la posibilidad de retirar la postulación del artículo o de incluirlo en el banco de artículos del próximo número.

El editor y los editores de sección de la Revista de Arquitectura (Bogotá) son los encargados de establecer contacto entre los autores y revisores, ya que estos procesos se realizan de manera anónima.
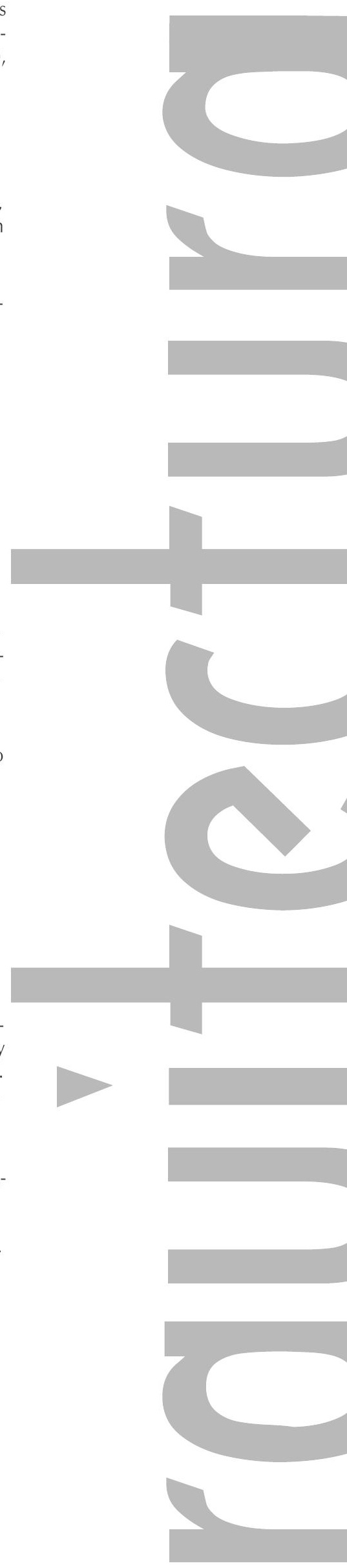

\section{.}

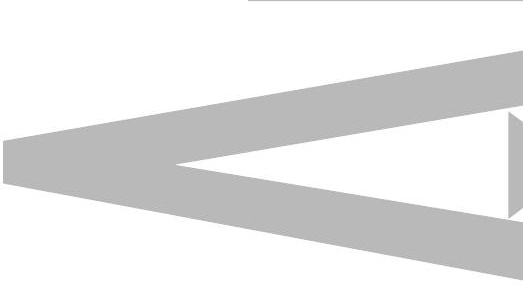


Los artículos científicos como herramienta de aprendizaje en las escuelas de arquitectura

نं Scientific articles as a learning tool in architecture schools

$\ll \quad$ Os artigos científicos como ferramenta de aprendizagem

nas escolas de arquitetura

Carolina Rodriguez-Ahumada

Paisaje urbano y espacio público como expresión 으 de la vida cotidiana

Urban landscape and public space as an expression of everyday life

نั Paisagem urbana e espaço público como expressão da vida cotidiana

Habitar la quebrada: conformación de gradientes en las trazas 을 vernaculares de los sectores altos de Valparaíso

Inhabiting the ravine: Gradient configuration in the vernacular layouts of the

¿ higher sectors of Valparaíso

Habitar a quebrada: conformação de níveis nos traçados vernaculares dos setores altos de Valparaíso

\section{Omar Eduardo Canete-Islas}

Juan Luis Moraga-Lacoste

Felipe Mateo López-Flores

Láminas cilíndricas en la arquitectura colombiana del siglo $X X$ Cylindrical shells in Colombian architecture in the 20th century

Estruturas laminares cilíndricas na arquitetura colombiana do século $X X$ 这 Jorge Galindo-Díaz

Retórica simbólica en el espacio arquitectónico. Una mirada antropológica de la casa en la sobremodernidad

in Symbolic Rhetoric in the Architectural Space: An Anthropological View of the

ن House in the Age of Supermodernity

Retórica simbólica no espaço arquitetônico. Um olhar antropológico da casa na sobremodernidade

\section{Eska Elena Solano-Meneses}

Ecoenvolventes: análisis del uso de fachadas ventiladas en clima ㅈ cálido-húmedo

نं Eco-friendly coverings: Analysis of the use of ventilated facades in hot, humid

ن⿺ weather

Ecoenvolventes: análise do uso de fachadas ventiladas em clima quente úmido

Sara Luciani-Meía

Rodrigo Velasco-Gómez

Roland Hudson

Estrategias metodológicas de análisis urbano frente al cambio œ climático. Matriz para el diseño adaptativo en asentamientos $\stackrel{\infty}{\text { informales }}$

Methodological strategies for urban analysis in the face of climate change. An adaptive design matrix for informal settlements

Estratégias metodológicas de análise urbana ante mudanças climáticas. Matriz para o desenho adaptativo em assentamentos informais

Adriana Patricia López-Valencia

Muro panel térmico estructural compuesto en guadua y - cartónModelo experimental aplicado al clima de la zona cafetera

․ Structural thermal panel wall composed of bamboo and cardboard.

Experimental model applied to the climate of the Coffee Region

$\ltimes$ Muro painel térmico estrutural composto de bambu e papelão. Modelo experimental aplicado ao clima da zona cafeeira

\section{Renato Cassandro-Cajiao}

Continuidad y transformaciones de modelos pedagógicos en la École Polytechnique (1867-1910)

으 Continuity and transformations of teaching models at the École Polytechnique

二 (1867-1910)

ن Continuidade e transformações de modelos pedagógicos na École

¿ Polytechnique (I867-1910) 